\title{
Genetic compensation is triggered by mutant mRNA degradation
}

Mohamed A. El-Brolosy ${ }^{1}$, Andrea Rossi ${ }^{1}$, Zacharias Kontarakis ${ }^{1}$, Carsten Kuenne ${ }^{2}$, Stefan Günther $^{2}$, Nana Fukuda ${ }^{1}$, Carter Takacs ${ }^{3,}$, Shih-Lei Lai ${ }^{1, \text { b }}$, Ryuichi Fukuda ${ }^{1}$, Claudia Gerri ${ }^{1, \mathrm{c}}$, Khrievono Kikhi ${ }^{1}$, Antonio J. Giraldez ${ }^{3}$ and Didier Y.R. Stainier ${ }^{1} *$

${ }^{1}$ Department of Developmental Genetics, Max Planck Institute for Heart and Lung Research, Bad Nauheim, Germany

${ }^{2}$ ECCPS Bioinformatics and Deep Sequencing Platform, Max Planck Institute for Heart and Lung Research, Bad Nauheim, Germany

${ }^{3}$ Department of Genetics, Yale University School of Medicine, New Haven, USA.

${ }^{\mathrm{a}}$ Present address: University of New Haven, New Haven, USA.

${ }^{b}$ Present address: Institute of Biomedical Sciences, Academia Sinica, Taipei, Taiwan.

${ }^{c}$ Present address: The Francis Crick Institute, London, UK.

*Correspondence to: didier.stainier@mpi-bn.mpg.de 
Genetic compensation by transcriptional modulation of related gene(s) (also known as transcriptional adaptation) has been reported in numerous systems ${ }^{1-3}$; however, whether and how such a response can be activated in the absence of protein feedback loops is unknown. Here, we develop and analyze several models of transcriptional adaptation in zebrafish and mouse that we show are not caused by loss of protein function. We find that the increase in transcript levels is due to enhanced transcription, and observe a correlation between the levels of mutant mRNA decay and transcriptional upregulation of related genes. To assess the role of mutant mRNA degradation in triggering transcriptional adaptation, we use genetic and pharmacological approaches and find that mRNA degradation is indeed required for this process. Notably, uncapped RNAs, themselves subjected to rapid degradation, can also induce transcriptional adaptation. Next, we generate alleles that fail to transcribe the mutated gene and find that they do not show transcriptional adaptation, and exhibit more severe phenotypes than those observed in alleles displaying mutant mRNA decay. Transcriptome analysis of these different alleles reveals the upregulation of hundreds of genes with enrichment for those showing sequence similarity with the mutated gene's mRNA, suggesting a model whereby mRNA degradation products induce the response via sequence similarity. These results expand the role of the mRNA surveillance machinery in buffering against mutations by triggering the transcriptional upregulation of related genes. Besides implications for our understanding of disease-causing mutations, our findings will help design mutant alleles with minimal transcriptional adaptation-derived compensation.

Recent advances in reverse genetic tools have greatly enhanced our ability to study gene function in a much wider range of organisms. These studies have reinforced previous observations that many engineered mutants do not exhibit an obvious phenotype, reviving interest in the concept of 
genetic robustness. Several mechanisms have been proposed to explain genetic robustness, including functional redundancy ${ }^{4}$, rewiring of genetic networks ${ }^{5}$, and the acquisition of adaptive mutations in the case of rapidly proliferating organisms such as yeast ${ }^{6}$. In a previous report ${ }^{1}$, we proposed genetic compensation as another underlying mechanism, whereby a deleterious mutation can lead to the transcriptional upregulation of related genes which can assume the function of the mutated gene. We provided evidence that this upregulation is induced upstream of the loss of protein function, implying the existence of an unknown trigger. In order to investigate the molecular machinery underlying genetic compensation, we developed and investigated zebrafish and mouse mutants that display transcriptional adaptation, a form of genetic compensation that involves the transcriptional upregulation of genes that can potentially compensate for the loss of the mutated gene.

We started by analyzing different zebrafish mutants, namely hbegfa, vcla, hiflab, vegfaa, egfl7 and alcama mutants, and found that they transcriptionally upregulate a paralogue or a family member (hereafter referred to as 'adapting genes'), namely hbegfb, vclb, epas $1 a$ and epas $1 b$, vegfab, emilin3a and alcamb, respectively (Fig. 1a). Moreover, we found that vcla, hiflab and egfl7 heterozygous animals also display a transcriptional adaptation response, albeit less pronounced than that observed in the homozygous mutants (Extended Data Fig. 1a), indicating that transcriptional adaptation is a dominant phenomenon. We also observed upregulation of the hbegfa, hiflab, vegfaa and alcama wild-type (wt) alleles in the respective heterozygous mutants (Extended Data Fig. 1b). Injection of wt hiflab, vegfaa, egfl7 and alcama mRNA into the respective mutants did not dampen the transcriptional adaptation response (Fig. 1b), indicating that the response is triggered upstream of the loss of protein function. These data are consistent with our previous observations that embryos injected with a dominant negative version of Vegfaa do not exhibit upregulation of vegfab mRNA levels even though they appear similar to vegfaa 
mutants ${ }^{1}$. Similarly, we found that Kindlin-2 mutant mouse kidney fibroblasts (MKFs), Rela and Actg1 mutant mouse embryonic fibroblasts (MEFs) and Actb mutant mouse embryonic stem cells (mESCs) (hereafter referred to as the knockout (K.O.) alleles) transcriptionally upregulate Kindlin-1, Rel, Actg2 and Actg1, respectively (Fig. 1c). Actb heterozygous mESCs also upregulate Actgl (Extended Data Fig 1b). Transfection of wt Kindlin-2 and Rela in the respective mutant cells also did not dampen the transcriptional adaptation response (Fig. 1d and Extended Data Fig. 2). Altogether, these data strongly indicate that the loss of protein function is not the trigger for the transcriptional adaptation response observed in these models.

To determine whether the increase in mRNA levels was due to increased transcription of the adapting genes or increased mRNA stability, we measured pre-mRNA levels of $h b e g f b$ and emilin $3 a$ in hbegfa and egfl7 mutants and found that they were upregulated to a similar extent as the mature mRNA (Extended Data Fig. 3a). Similar findings were obtained for Kindlin-1 and Rel pre-mRNA levels in Kindlin-2 and Rela K.O. cells (Extended Data Fig. 3b). Together, these data imply an increase in transcription of the adapting genes. To investigate the chromatin changes accompanying the transcriptional adaptation response, we performed ATAC-seq and found that Kindlin-2 K.O. MEFs display increased chromatin accessibility at the Kindlin-1 promoter region as well as at a potential enhancer region recently identified by $\mathrm{Hi}-\mathrm{C}$ analysis ${ }^{7,8}$ (Extended Data Fig. 3c). Similarly, the Rela K.O. MEFs display increased chromatin accessibility at a potential Rel enhancer region, also identified by Hi-C analysis ${ }^{7,8}$ (Extended Data Fig. 3d).

Since the loss of protein function does not appear to be the trigger for the transcriptional adaptation response, we investigated two other possible triggers, the DNA lesion and the mutant mRNA. We first reasoned that if the DNA lesion itself was the trigger for the transcriptional adaptation response, all mutations should induce it. However, some hbegfa, vcla, vegfaa and 
egfl7 mutant alleles do not display transcriptional adaptation (Extended Data Fig. 4a, b, c), indicating that the DNA lesion is not the trigger. While analyzing various mutant alleles, we found that two different alleles for hbegfa and vcla behave differently in terms of transcriptional adaptation. While the previously mentioned CRISPR-generated alleles of hbegfa (hereafter referred to as $h b e g f a^{\Delta 7}$ ) and vcla (hereafter referred to as $v c l a^{\Delta 13}$ ) display transcriptional upregulation of $h b e g f b$ and $v c l b$, respectively, ENU-induced alleles ( $h b e g f a^{\text {sal18135 }}$ and $v c l a^{\text {sal4599 }}$ ) do not display transcriptional adaptation (Fig. 2a). For both genes, both alleles lead to a premature termination codon (PTC) in similar regions of the coding sequence. To investigate these differences further, we examined the degradation of the mutant mRNA in the various alleles, and observed that the extent of the transcriptional adaptation response correlated with the levels of mutant mRNA decay. For example, while the $h b e g f a^{\Delta 7}$ allele displays a $50 \%$ reduction in mutant transcript levels, the $h b e g f a^{\text {sa18135 }}$ allele displays only a $20 \%$ decrease; and similarly, while the $v c l a^{413}$ allele displays an $80 \%$ reduction in mutant transcript levels, the $v c l a^{\text {sal4599 }}$ allele displays no noticeable decrease (Fig. 2b). Moreover, we observed that all of the previously mentioned zebrafish and mouse models of transcriptional adaptation display mutant mRNA decay (Fig. 2c, d). In contrast, alleles that fail to induce a transcriptional adaptation response do not display mutant mRNA decay (Extended Data Fig. 4a, b, c). To confirm that the observed reduction of mutant transcript levels was due to mRNA decay and not decreased transcription of the mutated gene, we analyzed the pre-mRNA levels of hbegfa, egfl7 and alcama in $h b e g f a^{47}$, egfl7 and alcama mutant zebrafish, and found that unlike the mRNA, the pre-mRNA levels remained unchanged, or were slightly upregulated, compared to wt (Extended Data Fig. 5a). Similar findings were observed in Kindlin-2 and Rela K.O. cells (Extended Data Fig. 5b). Thus, mutants that exhibit transcriptional adaptation show reduced mutant mRNA levels due to mRNA decay. 
Mutant transcripts with a PTC are usually degraded through the nonsense-mediated decay (NMD) pathway. Upf1 is one of the key proteins that help detect PTCs and trigger the NMD pathway ${ }^{9}$. To investigate the role of the mRNA surveillance machinery in triggering transcriptional adaptation to mutations, we genetically inactivated the NMD pathway in $h b e g f a^{\Delta 7}$, vegfaa and $v c l a^{\Delta 13}$ zebrafish mutants. Inactivating upfl in these mutants led to decreased levels of mutant mRNA decay and also to the loss of transcriptional adaptation (Fig. 2e and Extended Data Fig. 6a). Similar findings were obtained when knocking down UPF1 and EXOSC4 (a component of the exosome complex required for $3^{\prime}$ to $5^{\prime}$ 'degradation of defective transcripts) in Rela K.O. MEFs, or when knocking down SMG6 (another key protein of the mRNA surveillance machinery) in Actb K.O. mESCs (Extended Data Fig. 6b, c), and also when pharmacologically inhibiting NMD in hbegfa ${ }^{47}$ zebrafish mutants (Extended Data Fig. 6d).

We next asked whether inducing mRNA decay in wt zebrafish or mouse cells by using uncapped mRNAs, which are known to be rapidly degraded by 5 ' to $3^{\prime}$ exonucleases ${ }^{10}$, would induce a transcriptional adaptation response. Indeed, we found that injection of uncapped hiflab or vegfaa mRNAs into wt embryos induced a transcriptional adaptation response (Fig. $2 \mathrm{f}$ and Extended Data Fig. 6e) as well as an increase in endogenous hiflab and vegfaa gene expression (data not shown). Similarly, transfection of uncapped Actb into wt mESCs led to Actgl upregulation (Extended Data Fig. 6f). Notably, injection of uncapped hiflab or vegfaa mRNAs with an upstream sequence which makes them resistant to $5^{\prime}$ to $3^{\text {' }}$ exonuclease-mediated decay ${ }^{11}$ did not induce a transcriptional adaptation response (data not shown). Taken together, these data indicate that mRNA degradation is sufficient to induce a transcriptional adaptation response.

Next, we reasoned that if the process of mutant mRNA degradation is the trigger for the transcriptional adaptation response, alleles that fail to transcribe the mutated gene should not 
display this response. To this end, we used CRISPR/Cas9 technology to generate such alleles (hereafter referred to as RNA-less alleles) through deletion of the promoter region or the entire gene locus (for compact genes). Indeed, RNA-less alleles of hbegfa, vegfaa and alcama failed to upregulate hbegfb, vegfab and alcamb (Fig. 3a). Similarly, in mouse cells, RNA-less alleles of Rela, Actgl and Actb failed to exhibit a transcriptional adaptation response (Fig. 3b). We also attempted to generate a promoter-less allele for Kindlin-2 in MKFs; however, the obtained clones exhibited proliferation defects that prevented their expansion. As an alternative, we used CRISPR interference (CRISPRi) and found that reducing transcription of the mutant Kindlin-2 gene in Kindlin-2 K.O. cells led to a decrease in Kindlin-1 transcriptional upregulation (Extended Data Fig. 6g). RELA and REL are NF- $\mathrm{BB}$ transcription factors that play an essential role in preventing tumor necrosis factor $\alpha(\mathrm{TNF} \alpha)$ mediated apoptosis ${ }^{12}$. We observed that the promoter-less Rela MEFs were more sensitive to TNF $\alpha$-induced apoptosis than the Rela K.O. MEFs (Fig. 3c). Moreover, mESCs with an Actb full locus deletion displayed less protrusive activity and more severe growth defects than Actb K.O. cells did (Fig. 3d, e). We also generated an RNA-less allele for egfl7 and observed that the mutant embryos display pronounced vascular defects (Fig. 3f). Therefore, generation of RNA-less alleles can uncover phenotypes masked by transcriptional adaptation-derived compensation in mutant alleles that display mRNA decay.

Following mRNA decay, intermediates can be detected in the nucleus ${ }^{13}$, and small RNAs can modulate gene expression in a homology-mediated base-pairing fashion ${ }^{14-17}$. We thus reasoned that if mRNA decay intermediates act in a similar fashion to induce transcriptional adaptation, we should observe the upregulation of genes that exhibit sequence similarity with the mutated gene's mRNA. Transcriptome analysis of Kindlin-2, Actg1 and Actb K.O. cells revealed the upregulation of hundreds of genes in K.O. cells compared to wt, with no signs of a stress-induced response (Extended Data Fig. 7). Notably, we observed that at least $50 \%$ of protein-coding genes 
exhibiting sequence similarity with the mutated gene's mRNA (hereafter referred to as 'similar' genes) were significantly upregulated, compared to a maximum of $21 \%$ when looking at a random set of protein-coding genes (Fig. 4a and Extended Data Fig. 8). In addition, 7 out of the 12 upregulated 'similar' genes in Actg1 K.O. cells were not upregulated in Actg1 RNA-less cells, and 4 out of the 6 upregulated 'similar' genes in Actb K.O. cells were not upregulated in Actb RNA-less cells (Extended Data Fig. 8). We then tested whether sequence similarity was sufficient to induce transcriptional adaptation. Mouse Actb and zebrafish $a c t b 1 \mathrm{mRNAs}$ exhibit a high degree of sequence similarity, and injection of uncapped mouse Actb mRNA into zebrafish embryos led to the upregulation of zebrafish actbl (Fig. 4b). On the other hand, injection of uncapped transcripts corresponding to the antisense strands of hiflab and vegfaa mRNAs did not induce a transcriptional adaptation response (Fig. 4c), unlike what was observed with the sense strands (Fig. 2f). Moreover, injection of an uncapped synthetic transcript containing only sequences of hiflab mRNA similar to the epasla genomic locus was sufficient to induce a transcriptional adaptation response (Fig. 4d, Extended Data Fig. 9). Altogether these data suggest that transcriptional adaptation is induced in a sequence-similarity specific manner, possibly through mRNA decay intermediates (Fig. 4e).

Despite being a widely observed phenomenon ${ }^{3}$, transcriptional adaptation to mutations and its underlying molecular mechanisms remain poorly understood. Here we show that the mRNA surveillance machinery is important not only to prevent the translation of defective transcripts but also to buffer against mutations by triggering the transcriptional upregulation of related genes, including the wt allele of the mutated gene in the heterozygous state. In the past decade, it has become evident that the control of mRNA stability plays an important role in gene expression ${ }^{18-}$ 21. Previous studies have reported genetic and physical interactions of several mRNA decay factors with various proteins involved in gene expression, including RNA polymerase II and 
chromatin remodelers $^{22}$. Indeed, mRNA decay factors can translocate to the nucleus and promote gene expression in a manner dependent on their ability to degrade mRNA ${ }^{22}$. Accordingly, we found that inactivating key mRNA decay factors leads to the loss of transcriptional adaptation (Fig. 2e and Extended Data Fig. 6b). Although mRNA decay intermediates were reported to be present in the nucleus ${ }^{13}$, their biological relevance remains unclear. A previous study reported that transfection of short fragments of the Cdk9 or Sox9 mRNA can lead to an increase in expression of these genes ${ }^{15}$. Mechanistically, these RNA fragments were found to downregulate antisense transcripts produced from these loci and which normally act as negative regulators of $C d k 9$ and $\operatorname{Sox} 9$ expression. Interestingly, we found that transfection of uncapped $\operatorname{Cdk} 9$ or $\operatorname{Sox} 9$ RNA leads to a clear upregulation of these genes (Extended Data Fig. 10a). Moreover, knockdown of a BDNF antisense transcript was reported to lead to the upregulation of the sense transcript, a response that involved a decrease in the negative histone mark $\mathrm{H} 3 \mathrm{~K} 27 \mathrm{me} 3^{23}$. Notably, we observed that transfection of uncapped $B D N F$ sense transcript leads to a downregulation of the antisense transcript and a concomitant upregulation of the sense one (Extended Data Fig. 10b). These data indicate that acting on antisense transcripts is one possible mechanism through which mRNA decay intermediates can induce transcriptional adaptation in a sequence specific manner, a response that might also involve the modulation of histone marks.

Our study also provides clear guidelines towards generating mutant alleles that minimize compensation via transcriptional adaptation. We show that alleles that fail to transcribe the mutated gene do not exhibit transcriptional adaptation and can display phenotypes not observed in other mutant alleles (Fig. 3c-f). Consistent with our observations, a previous zebrafish study reported that mutant alleles for $m t 2$ with a lower degree of mutant mRNA decay display more severe phenotypes than alleles displaying a higher degree of mRNA decay ${ }^{24}$. For a number of human genetic diseases, several studies have reported that missense or in-frame indels, which are 
less likely to lead to mutant mRNA degradation, are more common in affected individuals than nonsense mutations or out-of-frame indels, which are more likely to lead to mutant mRNA degradation $^{25-30}$. Interestingly, a study on Marfan syndrome patients reported that when compared to individuals with $F B N 1$ missense mutations, the mildest form of the disease was observed in an individual displaying very low mutant FBN1 transcript levels due to an out-offrame indel leading to a PTC in the FBN1 coding sequence ${ }^{31}$. Similar results were observed in individuals with heterozygous nonsense mutations in the $H B B$ gene; individuals who displayed decay of the mutant $H B B$ transcripts were asymptomatic while individuals displaying no decay developed beta thalassemia-intermedia ${ }^{32}$. While the current dogma in the field is that missense mutations tend to be more common in some diseases as they may lead to constitutively active or dominant negative proteins, we propose that nonsense mutations might be less common in affected individuals as they might lead to mRNA decay-triggered compensatory upregulation of related genes and therefore not cause significant symptoms. Detailed transcriptomic analyses of relevant individuals will help test this hypothesis. Other studies have reported the upregulation of the wt allele in heterozygous conditions due to loss of negative feedback loops ${ }^{33,34}$. We found that transcriptional adaptation can also lead to the upregulation of the wt allele in heterozygous fish (Extended Data Fig. 1b), thus providing a possible explanation for haplosufficiency. Moreover, recent studies have reported homozygous loss-of-function mutations in several genes in healthy individuals (including genes such as EGFL7 and RELA studied here) ${ }^{35,36}$. It will be interesting to investigate whether degradation of the mutant transcripts is associated with a transcriptional adaptation response that protects these individuals. Such analyses may help us understand why some mutations cause disease while others do not. They may also help identify new modifier genes whose expression levels could be further modulated for therapeutic purposes. 


\section{References}

1 Rossi, A. et al. Genetic compensation induced by deleterious mutations but not gene knockdowns. Nature 524, 230-233, doi:10.1038/nature14580 (2015).

2 Tondeleir, D. et al. Cells lacking beta-actin are genetically reprogrammed and maintain conditional migratory capacity. Molecular \& cellular proteomics : MCP 11, 255-271, doi:10.1074/mcp.M111.015099 (2012).

3 El-Brolosy, M. A. \& Stainier, D. Y. R. Genetic compensation: A phenomenon in search of mechanisms. PLoS genetics 13, e1006780, doi:10.1371/journal.pgen.1006780 (2017).

4 Tautz, D. Redundancies, development and the flow of information. BioEssays : news and reviews in molecular, cellular and developmental biology 14, 263-266, doi:10.1002/bies.950140410 (1992).

5 Barabasi, A. L. \& Oltvai, Z. N. Network biology: understanding the cell's functional organization. Nat Rev Genet 5, 101-113, doi:10.1038/nrg1272 (2004).

6 Teng, X. et al. Genome-wide consequences of deleting any single gene. Molecular cell 52, 485494, doi:10.1016/j.molcel.2013.09.026 (2013).

7 Mendoza-Parra, M. A., Blum, M., Malysheva, V., Cholley, P. E. \& Gronemeyer, H. LOGIQA: a database dedicated to long-range genome interactions quality assessment. BMC genomics 17, 355, doi:10.1186/s12864-016-2642-1 (2016).

8 Giorgetti, L. et al. Structural organization of the inactive X chromosome in the mouse. Nature 535, 575-579, doi:10.1038/nature18589 (2016).

9 Isken, O. \& Maquat, L. E. Quality control of eukaryotic mRNA: safeguarding cells from abnormal mRNA function. Genes \& development 21, 1833-1856, doi:10.1101/gad.1566807 (2007). Mukherjee, C. et al. Identification of cytoplasmic capping targets reveals a role for cap homeostasis in translation and mRNA stability. Cell reports 2, 674-684, doi:10.1016/j.celrep.2012.07.011 (2012).

11 Boehm, V., Gerbracht, J. V., Marx, M. C. \& Gehring, N. H. Interrogating the degradation pathways of unstable mRNAs with XRN1-resistant sequences. Nature communications 7, 13691, doi:10.1038/ncomms13691 (2016).

Doi, T. S. et al. Absence of tumor necrosis factor rescues RelA-deficient mice from embryonic lethality. Proceedings of the National Academy of Sciences of the United States of America 96, 2994-2999 (1999).

13 Valen, E. et al. Biogenic mechanisms and utilization of small RNAs derived from human proteincoding genes. Nature structural \& molecular biology 18, 1075-1082, doi:10.1038/nsmb.2091 (2011).

$14 \mathrm{Li}$, L. C. et al. Small dsRNAs induce transcriptional activation in human cells. Proceedings of the National Academy of Sciences of the United States of America 103, 17337-17342, doi:10.1073/pnas.0607015103 (2006).

15 Ghanbarian, H. et al. Small RNA-directed epigenetic programming of embryonic stem cell cardiac differentiation. Scientific reports 7, 41799, doi:10.1038/srep41799 (2017). Zhang, X., Li, H., Burnett, J. C. \& Rossi, J. J. The role of antisense long noncoding RNA in small RNA-triggered gene activation. Rna 20, 1916-1928, doi:10.1261/rna.043968.113 (2014). Wagner, K. D. et al. RNA induction and inheritance of epigenetic cardiac hypertrophy in the mouse. Developmental cell 14, 962-969, doi:10.1016/j.devcel.2008.03.009 (2008). kinetics of gene induction. BMC genomics 11, 259, doi:10.1186/1471-2164-11-259 (2010). 
Rabani, M. et al. Metabolic labeling of RNA uncovers principles of RNA production and degradation dynamics in mammalian cells. Nat Biotech 29, 436-442, doi:10.1038/nbt.1861 (2011). genes encoding inflammatory molecules. Nat Immunol 10, 281-288, doi:10.1038/ni.1699 (2009). Sun, M. et al. Comparative dynamic transcriptome analysis (cDTA) reveals mutual feedback between mRNA synthesis and degradation. Genome research 22, 1350-1359, doi:10.1101/gr.130161.111 (2012). Haimovich, G. et al. Gene expression is circular: factors for mRNA degradation also foster mRNA synthesis. Cell 153, 1000-1011, doi:10.1016/j.cell.2013.05.012 (2013).

Modarresi, F. et al. Inhibition of natural antisense transcripts in vivo results in gene-specific transcriptional upregulation. Nature biotechnology 30, 453-459, doi:10.1038/nbt.2158 (2012). Schuermann, A., Helker, C. S. \& Herzog, W. Metallothionein 2 regulates endothelial cell migration through transcriptional regulation of vegfc expression. Angiogenesis 18, 463-475, doi:10.1007/s10456-015-9473-6 (2015). Ferec, C. \& Cutting, G. R. Assessing the Disease-Liability of Mutations in CFTR. Cold Spring Harbor Perspectives in Medicine 2, a009480, doi:10.1101/cshperspect.a009480 (2012). Myerowitz, R. Tay-Sachs disease-causing mutations and neutral polymorphisms in the Hex A gene. Human mutation 9, 195-208, doi:10.1002/(sici)1098-1004(1997)9:3<195::aidhumu1>3.0.co;2-7 (1997). Genschel, J. \& Schmidt, H. H. Mutations in the LMNA gene encoding lamin A/C. Human mutation 16, 451-459, doi:10.1002/1098-1004(200012)16:6<451::aid-humu1>3.0.c0;2-9 (2000).

Eisensmith, R. C. \& Woo, S. L. Molecular basis of phenylketonuria and related hyperphenylalaninemias: mutations and polymorphisms in the human phenylalanine hydroxylase gene. Human mutation 1, 13-23, doi:10.1002/humu.1380010104 (1992). Zhou, Q. et al. Early-onset stroke and vasculopathy associated with mutations in ADA2. The New England journal of medicine 370, 911-920, doi:10.1056/NEJMoa1307361 (2014). Chuzhanova, N. A., Anassis, E. J., Ball, E. V., Krawczak, M. \& Cooper, D. N. Meta-analysis of indels causing human genetic disease: mechanisms of mutagenesis and the role of local DNA sequence complexity. Human mutation 21, 28-44, doi:10.1002/humu.10146 (2003).

31 Dietz, H. C. et al. Four novel FBN1 mutations: significance for mutant transcript level and EGF-like domain calcium binding in the pathogenesis of Marfan syndrome. Genomics 17, 468-475, doi:10.1006/geno.1993.1349 (1993). Hall, G. W. \& Thein, S. Nonsense codon mutations in the terminal exon of the beta-globin gene are not associated with a reduction in beta-mRNA accumulation: a mechanism for the phenotype of dominant beta-thalassemia. Blood 83, 2031-2037 (1994).

Guidi, C. J., Veal, T. M., Jones, S. N. \& Imbalzano, A. N. Transcriptional compensation for loss of an allele of the Ini1 tumor suppressor. The Journal of biological chemistry 279, 4180-4185, doi:10.1074/jbc.M312043200 (2004). Trieu, M., Ma, A., Eng, S. R., Fedtsova, N. \& Turner, E. E. Direct autoregulation and gene dosage compensation by POU-domain transcription factor Brn3a. Development (Cambridge, England) 130, 111-121 (2003). Lek, M. et al. Analysis of protein-coding genetic variation in 60,706 humans. Nature 536, 285291, doi:10.1038/nature19057 (2016). Sulem, P. et al. Identification of a large set of rare complete human knockouts. Nature genetics 47, 448-452, doi:10.1038/ng.3243 (2015). 


\section{Methods}

Information on materials and methods can be found in the supplementary information.

\section{Acknowledgments}

We thank Vahan Serobyan, Arica Beisaw and Felix Gunawan for comments on the manuscript and Jenny Pestel for the alcama mutant. Wt and Kindlin-2 knockout MKFs were a generous gift from Reinhard Fässler (MPI for biochemistry, Martinsried, Germany). Wt and Rela knockout MEFs were a generous gift from Alexander Hoffmann (UCLA, USA). mESCs from the C57BL/6 mouse strain were a generous gift from Johnny Kim (MPI for heart and lung research, Bad Nauheim, Germany). We also thank Ann Atzberger for support with cell sorting and Martin Krzywinski for his help in drawing Figure 4e. M.A.E.B. was supported by a Boehringer Ingelheim Fonds PhD fellowship. Research in the Stainier lab is supported by the Max Planck Society, EU, DFG and Leducq Foundation.

\section{Author contributions}

Performed experiments (M.A.E.B., A.R., Z.K., N.F., S.G., C.K., and K.K.), provided unpublished mutants (C.T., S.L., R.F. and C.G.), supervised experiments (A.J.G. and D.Y.R.S.) and wrote the manuscript (M.A.E.B. and D.Y.R.S.); all authors commented on the manuscript.

\section{Competing financial interests.}

The authors declare no competing financial interests. 


\section{Figure legends}

Figure 1. Transcriptional adaptation models in zebrafish and mouse

a, qPCR analysis of hbegfb, vclb, epas $1 a$ and epas $1 b$, vegfab, emilin $3 a$ and alcamb mRNA levels in hbegfa, vcla, hiflab, vegfaa, egfl7 and alcama wt and mutant zebrafish. b, qPCR analysis of epas $1 a$ and epas $1 b$, vegfab, emilin $3 a$ and alcamb mRNA levels at 24 hours post fertilization (hpf) in hiflab, vegfaa, egfl7 and alcama mutant embryos injected with eGFP mRNA (control) or wt mRNA. c, qPCR analysis of Kindlin-1, Rel, Actg2 and Actg1 mRNA levels in Kindlin-2, Rela, Actg 1 and Actb wt and knockout cells. d, qPCR analysis of Kindlin- 1 and Rel mRNA levels in Kindlin-2 and Rela knockout cells transfected with empty vectors (control) or plasmids encoding wt KINDLIN-2 or RELA. a-d, Data points represent different biological replicates. Wt or control expression set at 1 for each assay. Error bars, s.d. Two-tailed student's $t$-test was used to assess $P$ values. *** $P \leq 0.01$, *** $P \leq 0.001$, **** $P \leq 0.0001$.

\section{Figure 2. Mutant mRNA decay induces transcriptional adaptation}

a, qPCR analysis of $h b e g f b$ and $v c l b$ mRNA levels in the indicated hbegfa and vcla mutant alleles. b, qPCR analysis of hbegfa and vcla mRNA levels in the indicated hbegfa and vcla mutant alleles. c, qPCR analysis of hiflab, vegfaa, egfl7 and alcama mRNA levels in hiflab, vegfaa, egfl7 and alcama wt and mutant zebrafish. d, qPCR analysis of Kindlin-2, Rela, Actg1 and Actb mRNA levels in Kindlin-2, Rela, Actg1 and Actb wt and knockout cells. e, qPCR analysis of hbegfa, hbegfb and vegfaa, vegfab mRNA levels in upfl;hbegfa or upfl;vegfaa double mutant zebrafish compared to the indicated controls. f, qPCR analysis of epas la and vegfab mRNA levels in 6 hpf wt embryos injected with uncapped hiflab and vegfaa mRNA. a-f, Data points represent different biological replicates. Wt or control expression set at 1 for each assay. Error bars, s.d. Two-tailed student's $t$-test was used to assess $P$ values. $* P \leq 0.05, * * P \leq 0.01$, $* * * P \leq 0.001, * * * * P \leq 0.0001$, ns: not significant.

\section{Figure 3. Alleles that fail to transcribe the mutated gene do not display transcriptional} adaptation and exhibit stronger phenotypes

a, qPCR analysis of hbegfa, hbegfb, vegfaa, vegfab, alcama and alcamb mRNA levels in zebrafish lacking the full hbegfa locus or the vegfaa or alcama promoter compared to wt siblings. b, qPCR analysis of Rela, Rel, Actb, Actg1, Actg1 and Actg2 mRNA levels in MEFs and mESCs lacking the Rela promoter or the full locus of Actg1 or Actb compared to wt cells. c, Cytotoxicity assay 24 hours following treatment of wt, Rela K.O. and Rela promoter-less MEFs with $25 \mathrm{ng} / \mathrm{ml}$ mouse TNF $\alpha$. Percentages were normalized relative to DMSO-treated cells. d, Confocal micrographs of wt, Actb K.O. and Actb full locus deletion mESCs. Actin filaments are depicted in white and nuclei in red. e, Actin filament protrusion length (in arbitrary units) in wt, Actb K.O. and Actb full locus deletion mESCs. f, Confocal micrographs of $48 \mathrm{hpf}$ Tg(flila:eGFP) wt and egfl7 full locus deletion -/- sibling embryos in lateral views. Higher magnifications of dashed 
boxes are shown in f'. Scale bars: e: $20 \mu \mathrm{m}, \mathbf{f}: 500 \mu \mathrm{m}$. a, b, Wt or control expression set at 1 for each assay. a-c, e, Data points represent different biological replicates. Error bars, s.d. Twotailed student's $t$-test was used to assess $P$ values. $* P \leq 0.05, * * P \leq 0.01$, *** $P \leq 0.001$, **** $P$ $\leq 0.0001$, ns: not significant.

Figure 4. Upregulation of genes exhibiting sequence similarity

a, RNA-seq analysis showing percentage of significantly upregulated protein-coding genes $\left(\log _{2}\right.$ Fold Change K.O. > wt and $P \leq 0.05$ ) for genes exhibiting sequence similarity with Kindlin-2, Actgl and Actb and for genes not exhibiting sequence similarity. b, qPCR analysis of $a c t b 1$ mRNA levels in 6 hpf wt embryos injected with uncapped mouse Actb mRNA. c, qPCR analysis of epasla and vegfab mRNA levels in $6 \mathrm{hpf}$ wt embryos injected with uncapped complementary transcripts of hiflab and vegfaa mRNA. d, qPCR analysis of epas la mRNA levels in $6 \mathrm{hpf} w \mathrm{t}$ embryos injected with uncapped RNA composed solely of the hiflab sequences similar to epas la. e, Current model of transcriptional adaptation to mutations. Red dot in mutated gene refers to a mutation. PTC: Premature termination codon; TC: Termination codon; DFs: Degradation factors; RBPs: RNA binding proteins. b-d, Control expression set at 1. Data points represent different biological replicates. Error bars, s.d. Two-tailed student's $t$-test was used to assess $P$ values. $* P \leq 0.05$, ** $P \leq 0.01$, *** $P \leq 0.001$, **** $P \leq 0.0001$. 
a

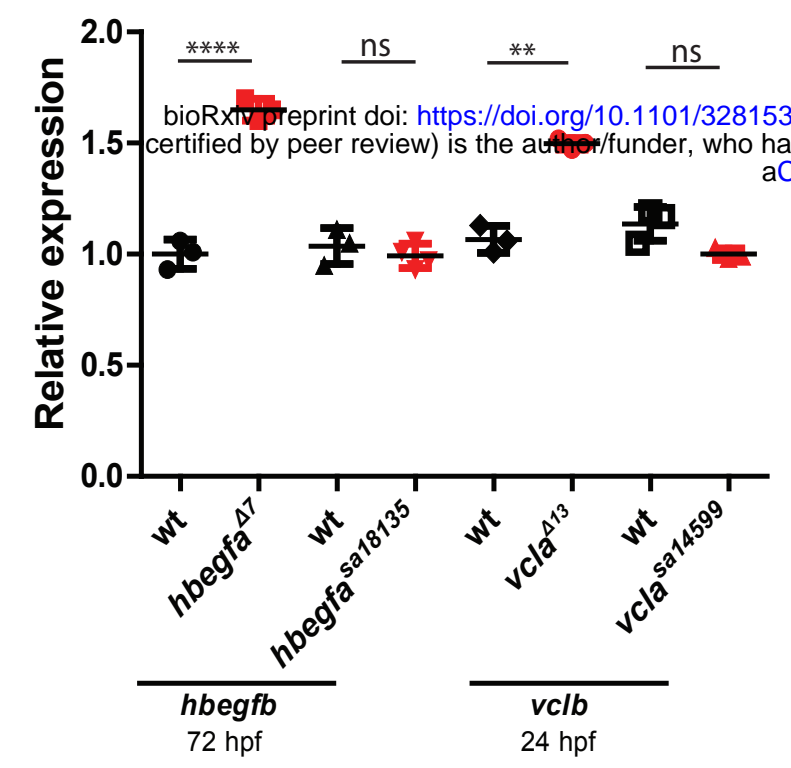

C

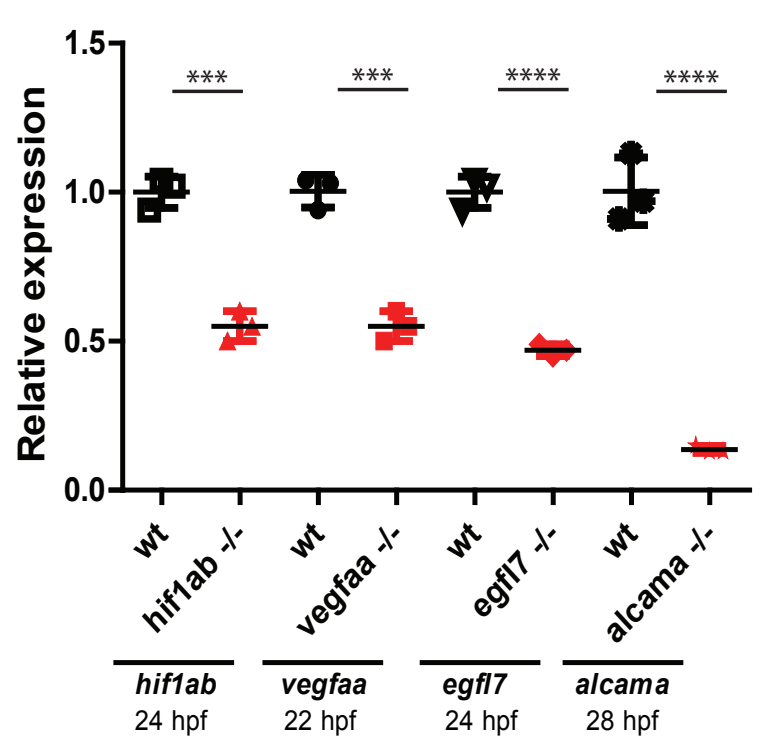

e

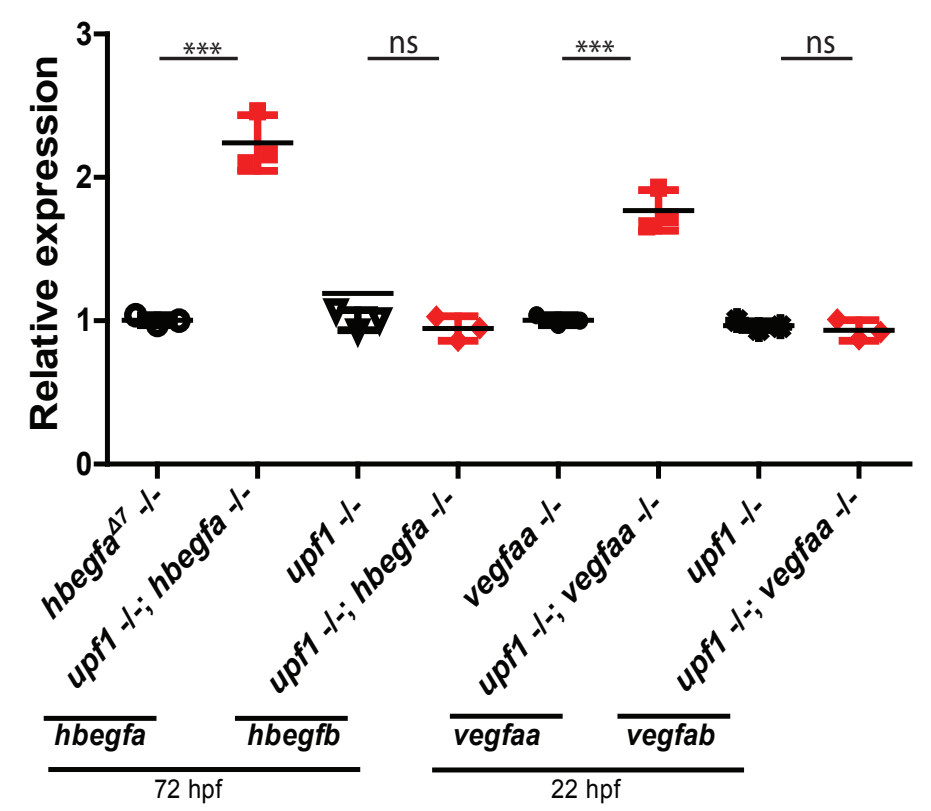

b

El-Brolosy et al. Figure 2
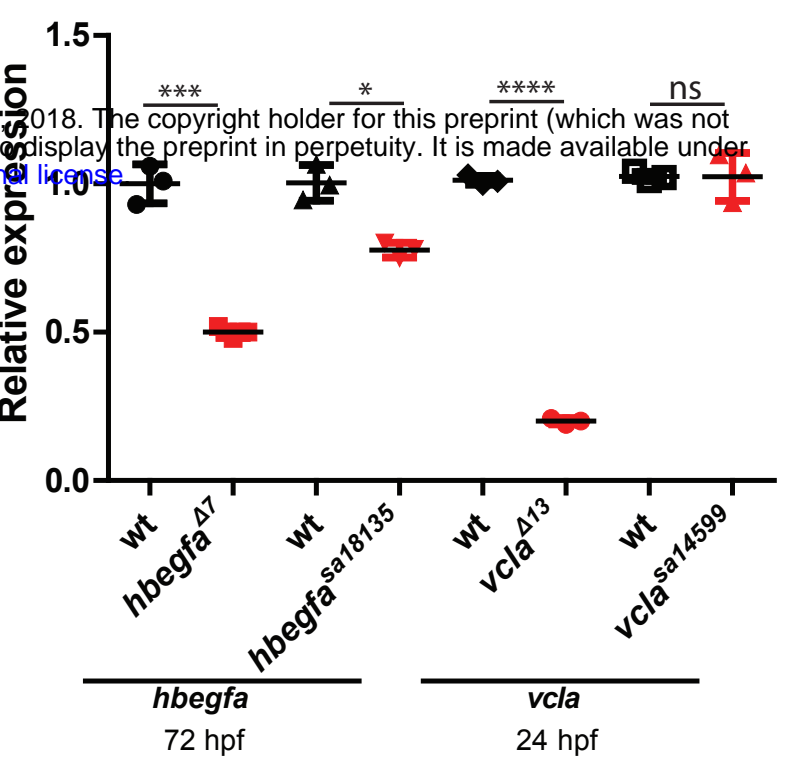

d

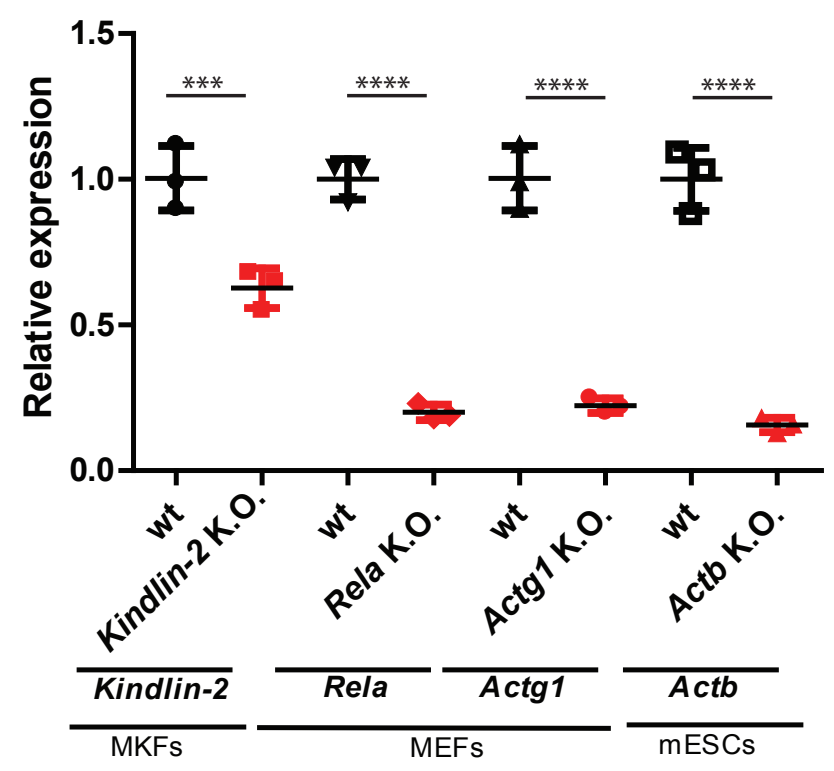

f

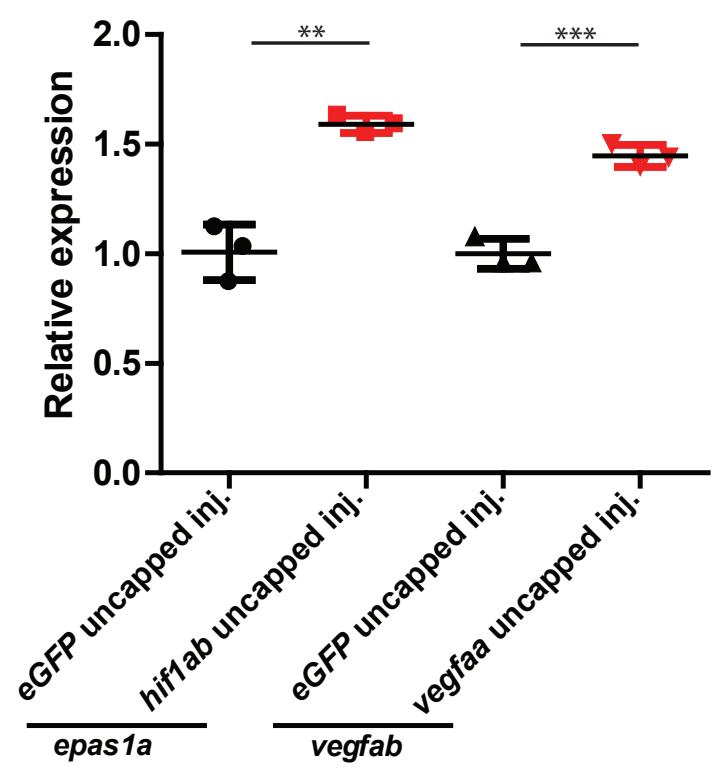




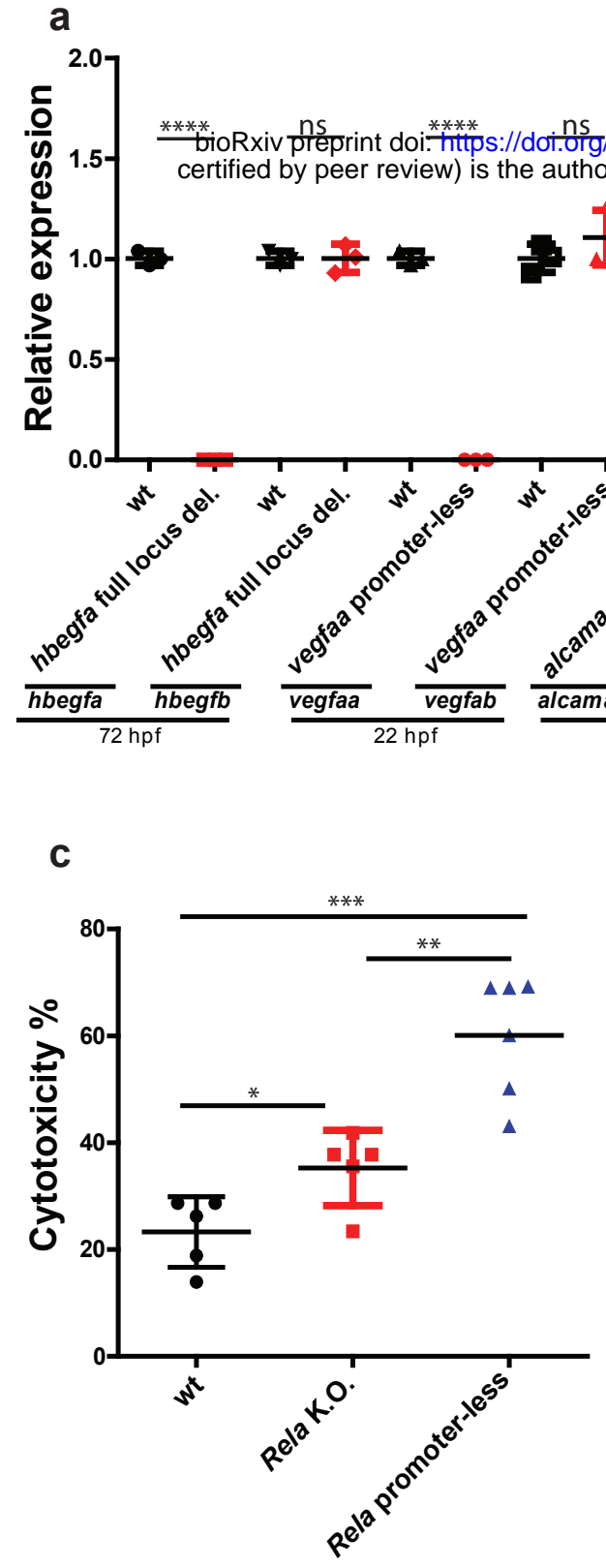

b

${ }^{1.5}{ }^{2}{ }^{* * * *} \quad \stackrel{n s}{* * * *}$ ns $\quad \stackrel{* * * *}{n}$ ns

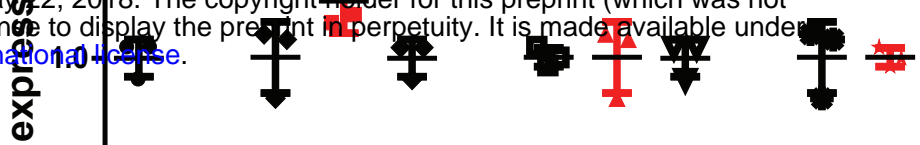
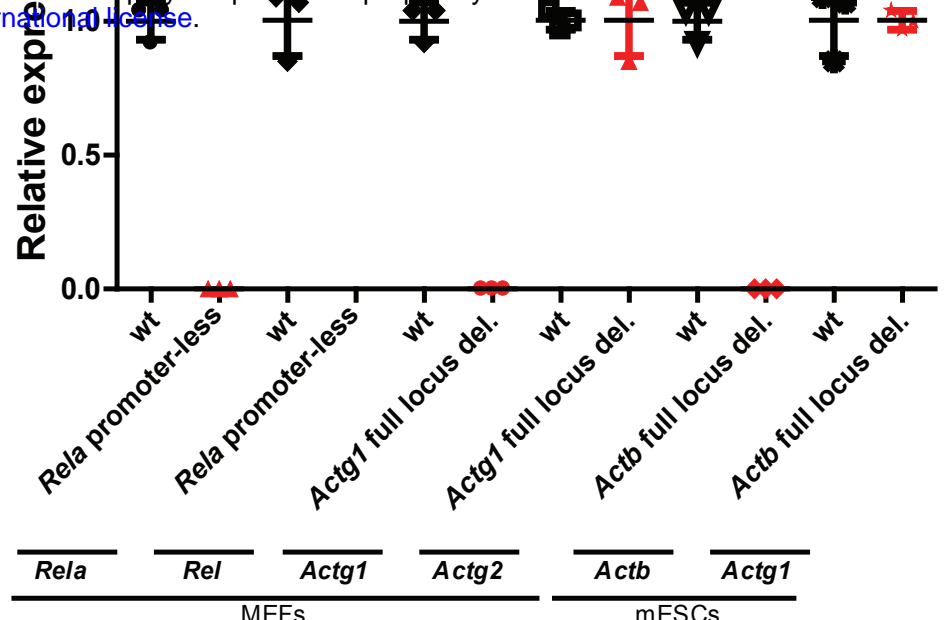

d
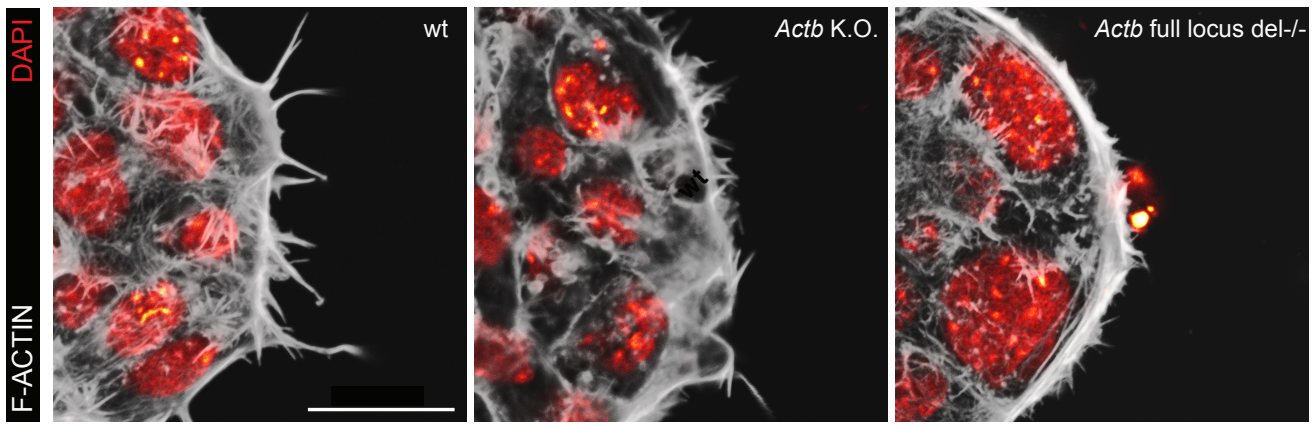

e

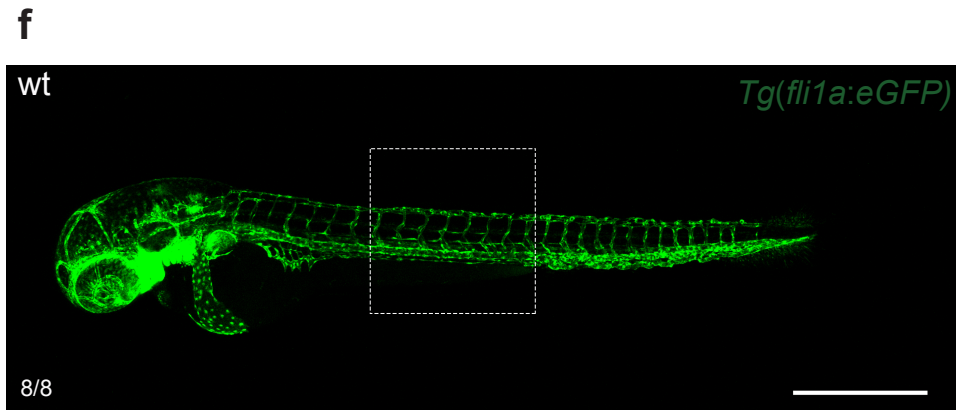

f

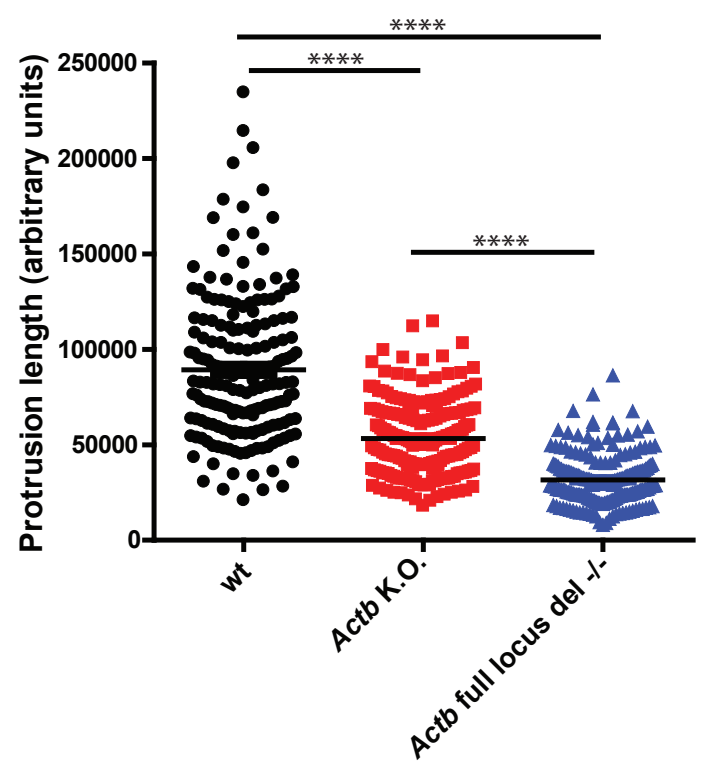

egfl7 full locus del -/-
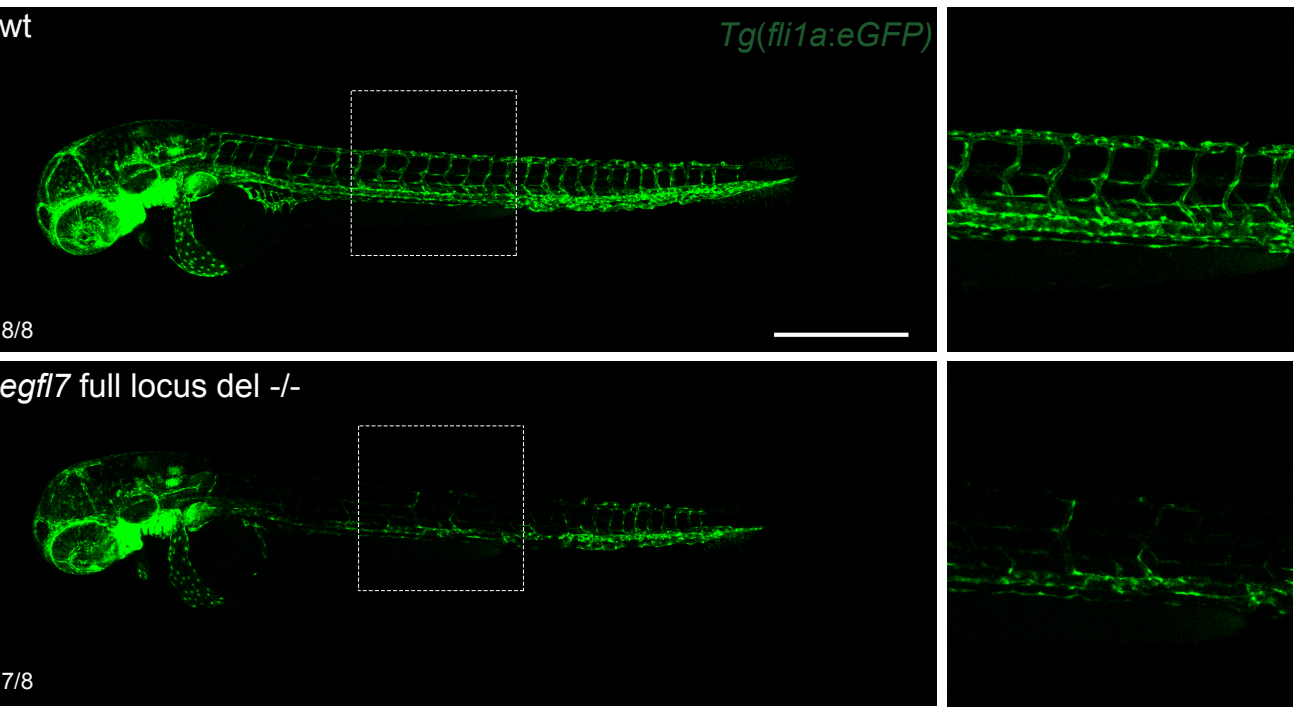
b

C

bioRxiv preprint doi: https://doi.org/10.1101/328153; this version posted May 22, 2018. The copyright holder for this preprint (which was not certified by peer review) is the author/funder, who has granted bioRxiv a license to display the preprint in perpetuity. It is made available under

Genes exhibiting sequence similarity

Genes not exhibiting sequence similarity
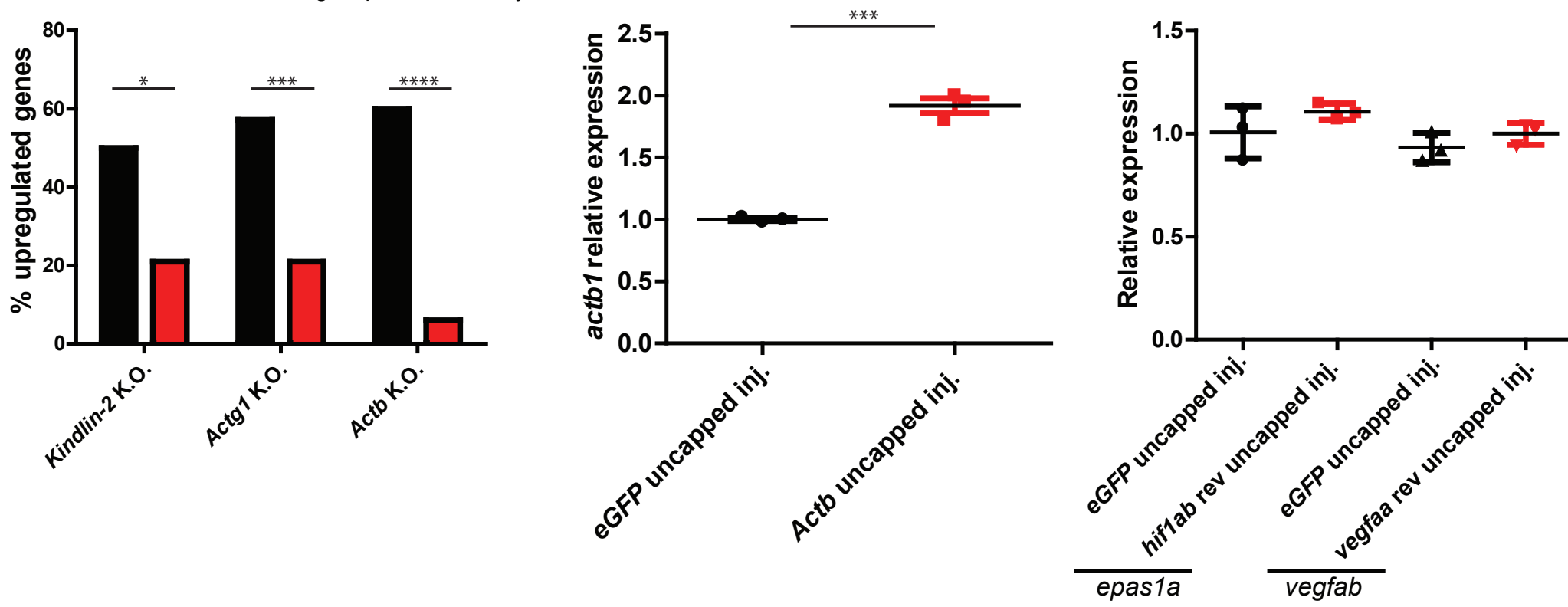

d

e
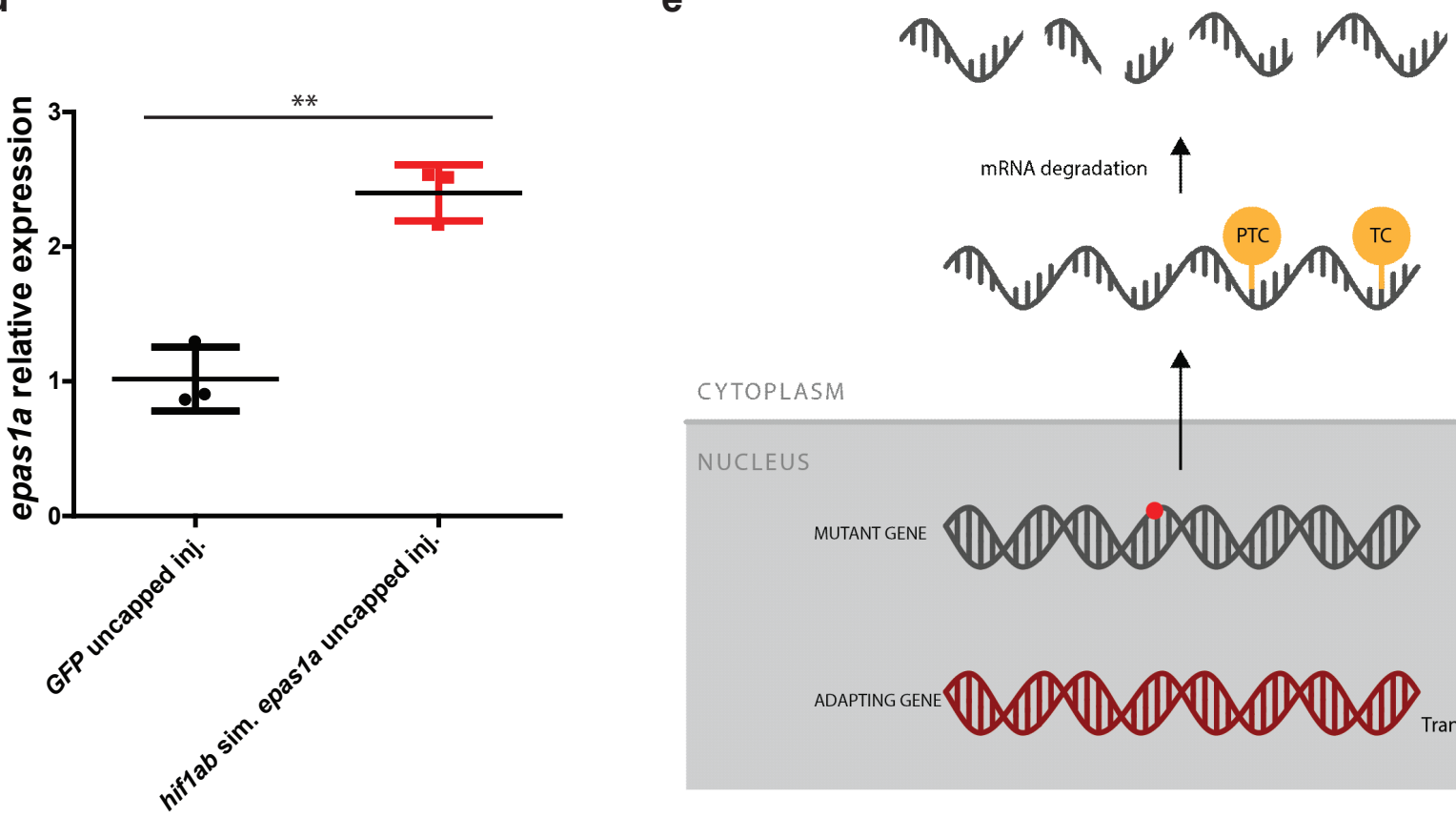

mRNA degradation

\section{$\uparrow$}

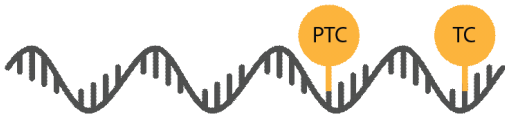

with DFs or

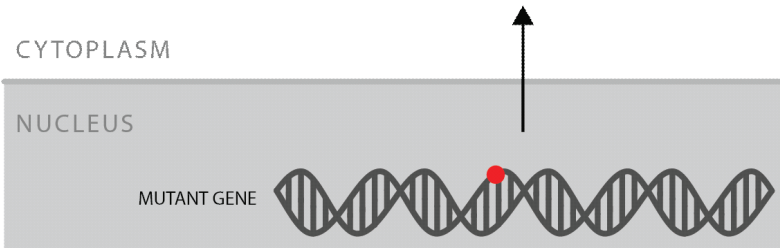

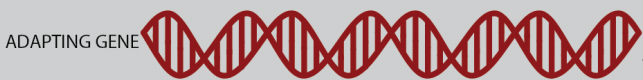


a

bioRxiv preprint doi: https://doi.org/10.1101/328153; this version posted May 22, 2018. The copyright holder for this preprint (which was not certified by peer review) is the author/funder, who has granted bioRxiv a license to display the preprint in perpetuity. It is made available under

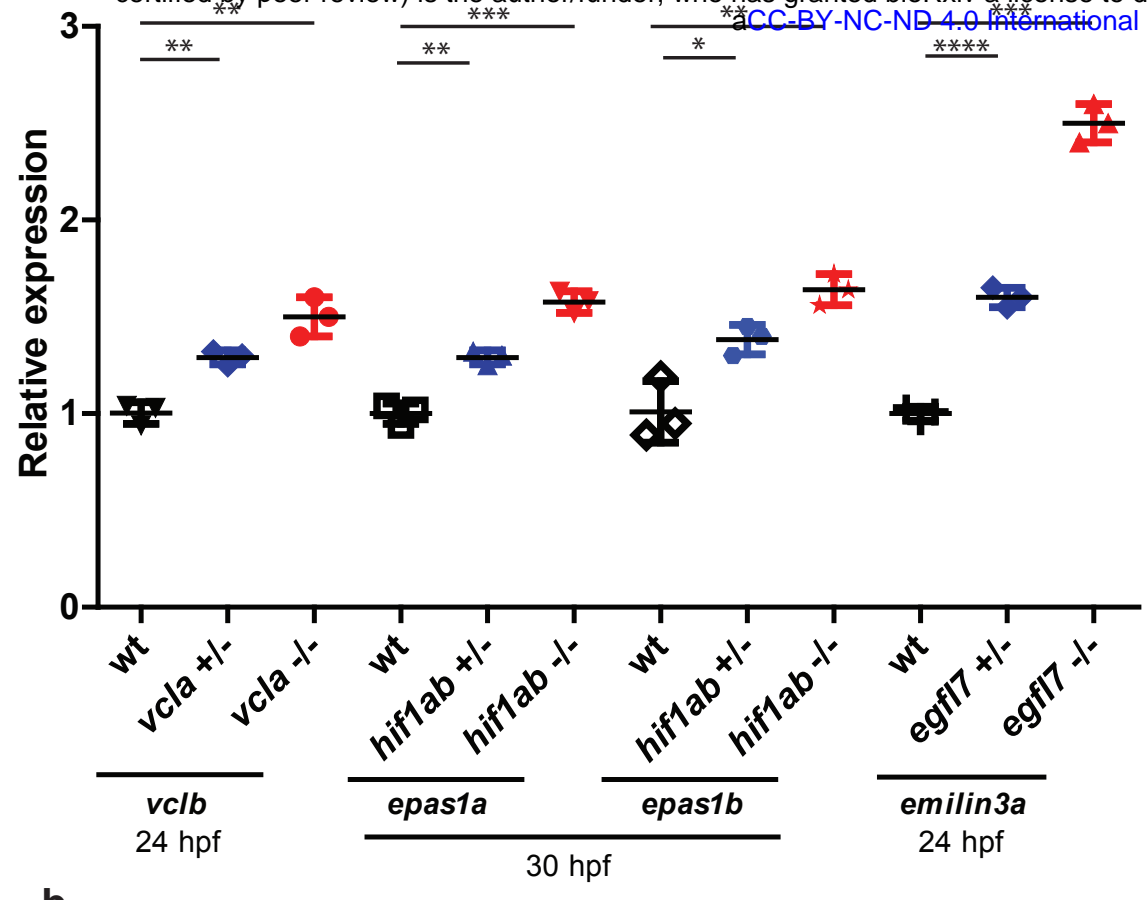

b

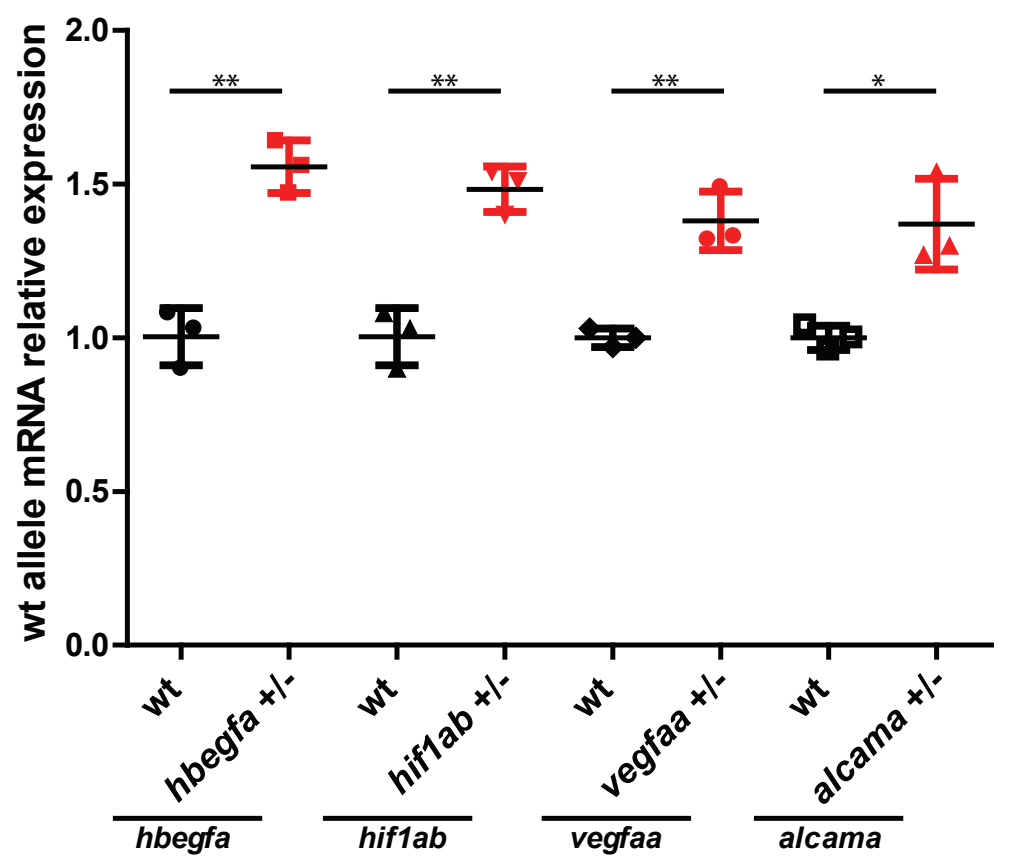

C

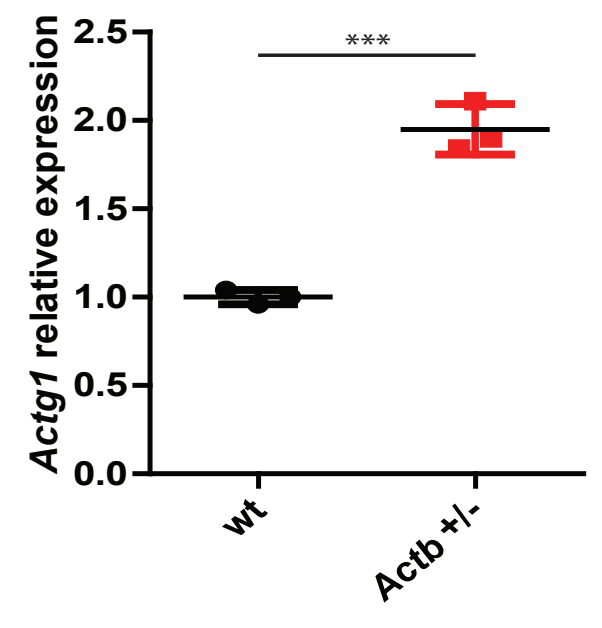


a cted

bioRxiv preprint doi: https://doi. 0 s $9940.1101 / 328153$; this version posted May 22, 2018. The copyright holderdor this preprint (which was not certified by peer review) is thexethor/funder, who has granted bioRxiv a license to display the preprint ingerpetuity. It is made available under aCC-BY-NC-ND 4.0 International license. ctit
KINDLIN-2

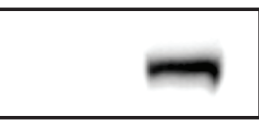
B-ACTIN

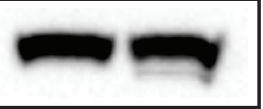 at kil
$70 \mathrm{kDa}$
$44 \mathrm{kDa}$

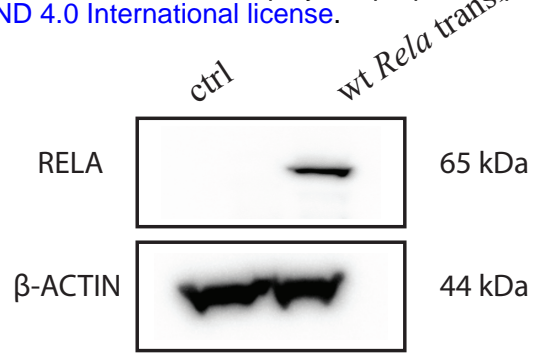


a

bioRxiv preprint doi: https://doi.org/10.1101/328153; this version posted May 22, 2018. The copyright holder for this preprint (which was not

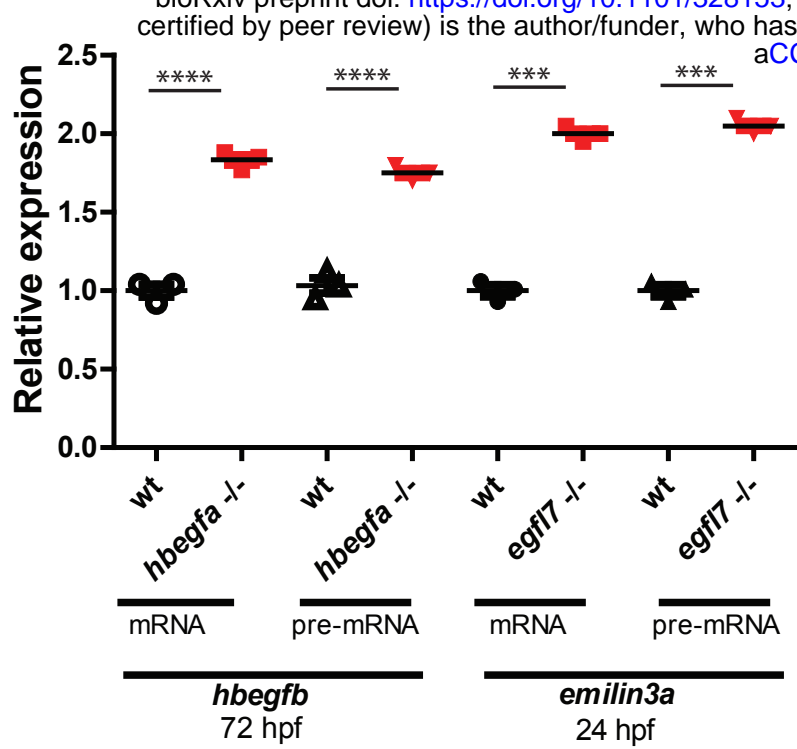

C
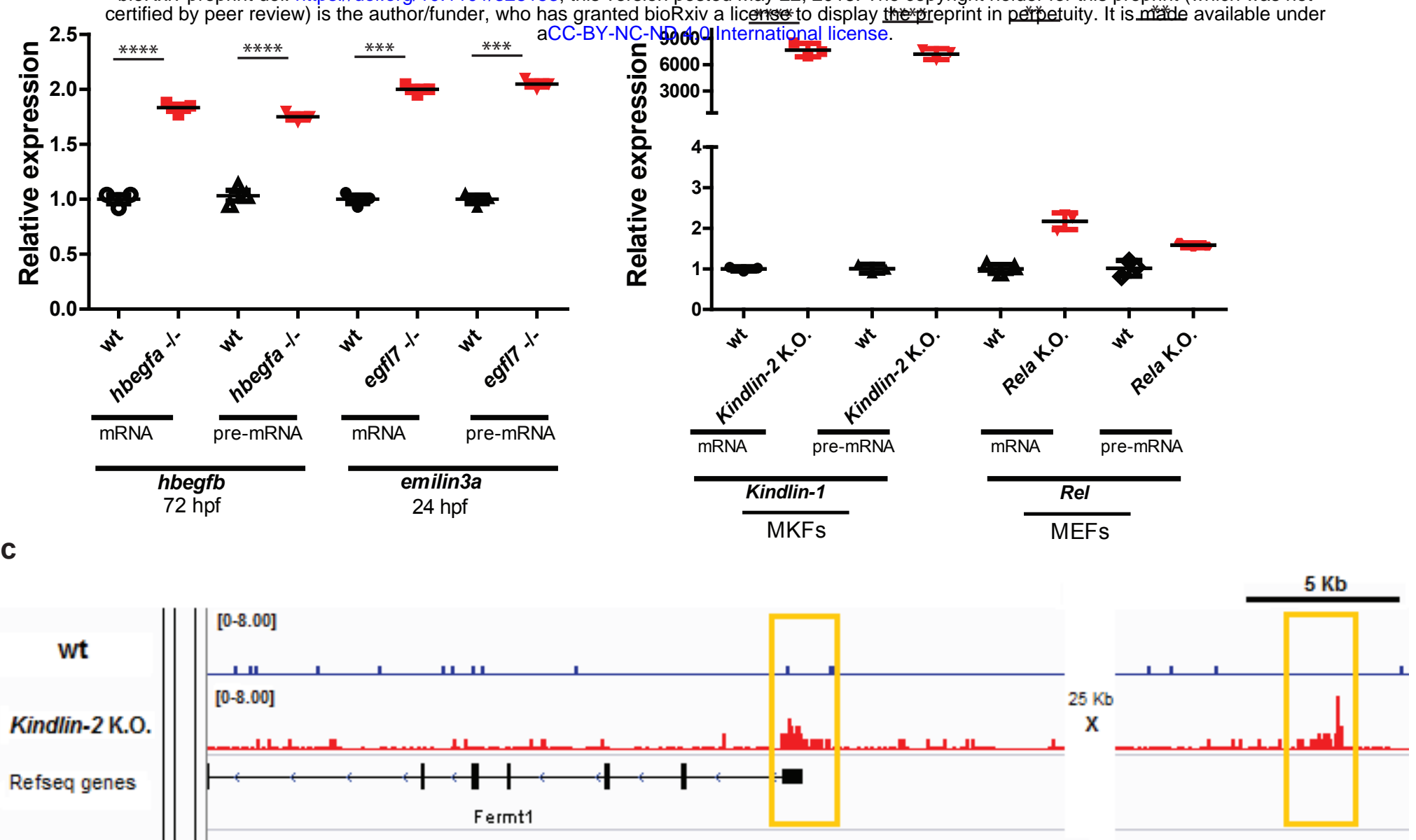

d

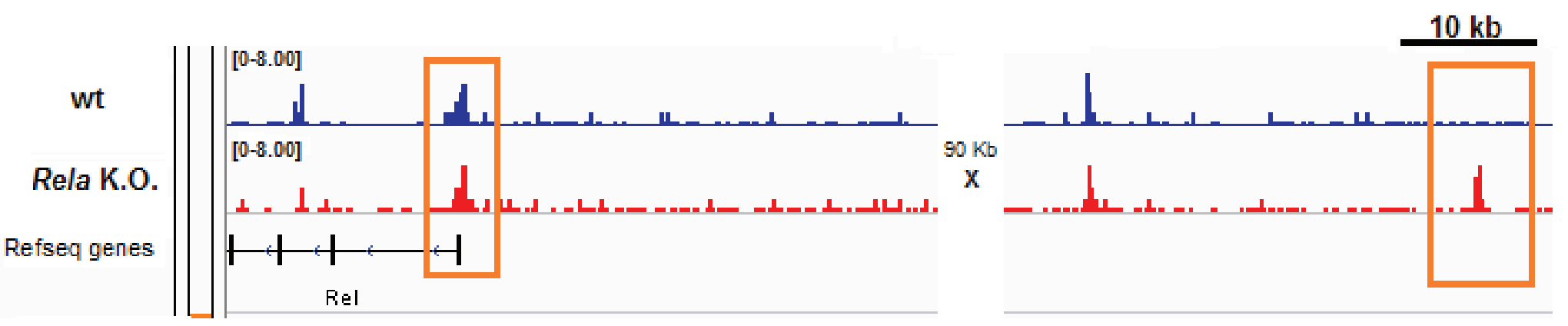



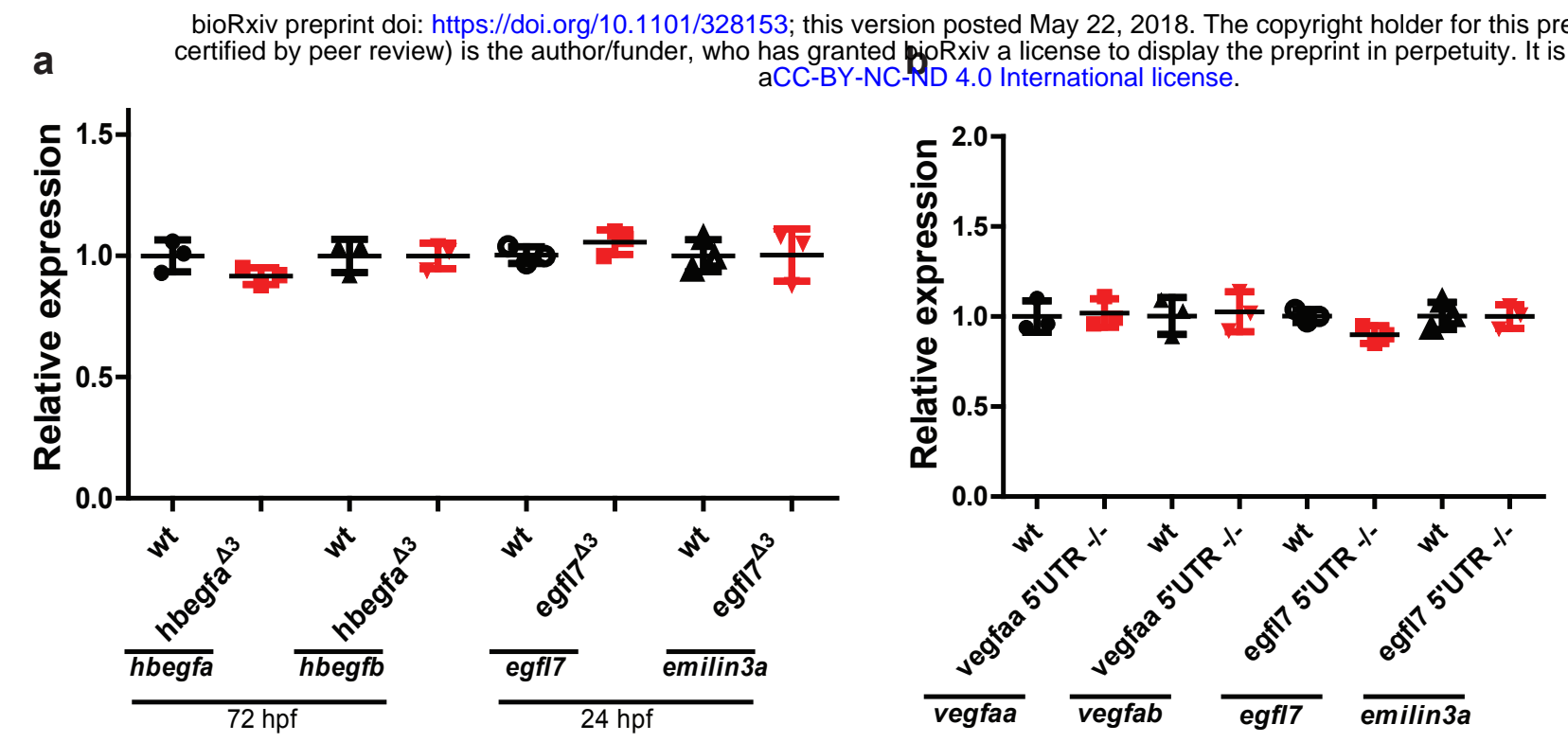

C

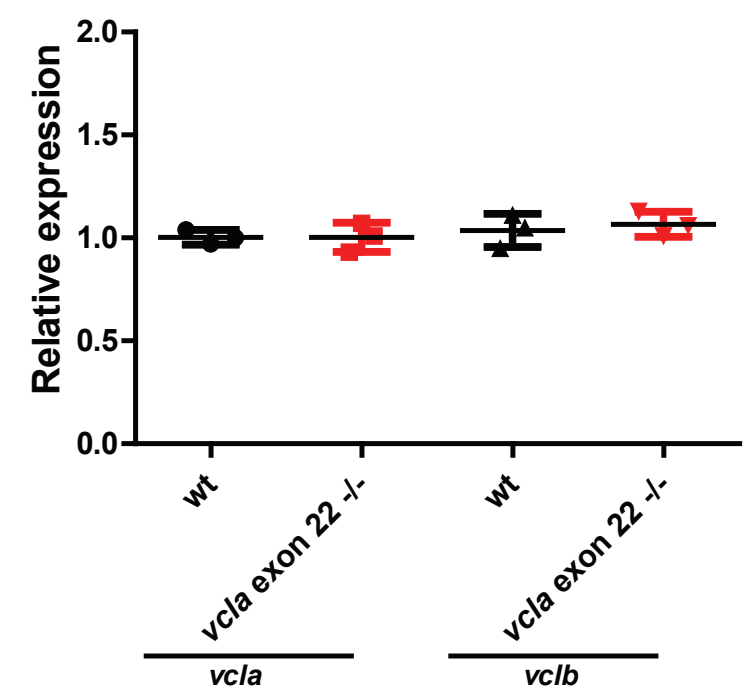


bioRxiv preprint doi: https://doi.org/10.1101/328153; this version posted May 22, 2018. The copyright holder for this preprint (which was not certified by peer review) is the author/funder, who has granted bioRxiv a license to display the preprint in perpetuity. It is made available under aCC-BY-NC-ND 4.0 Internatiolbal license.
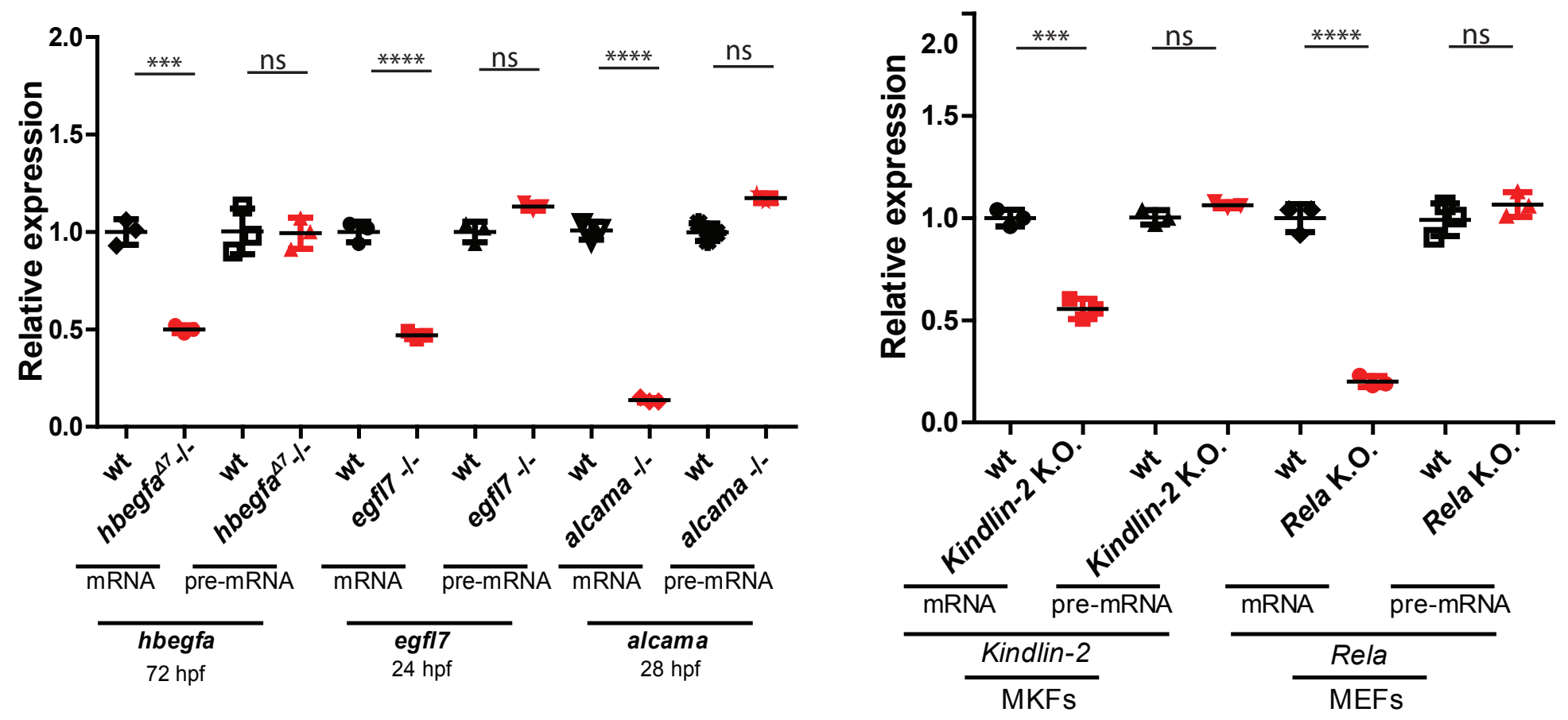


\begin{tabular}{|l|l|l|l|l|}
\hline & $\begin{array}{l}\text { No. of } \\
\text { upregulated } \\
\text { genes L2F > } \\
\mathbf{0 . 5 8 5}\end{array}$ & $\begin{array}{l}\text { No. of } \\
\text { upregulated } \\
\text { genes L2F K.O. } \\
\text { >wt }\end{array}$ & $\begin{array}{l}\text { No. of } \\
\text { downregulated } \\
\text { genes L2F <- } \\
\mathbf{0 . 5 8 5}\end{array}$ & $\begin{array}{l}\text { No. of } \\
\text { downregulated } \\
\text { genes L2F K.O. } \\
\text { <wt }\end{array}$ \\
\hline Kindlin-2 K.O. & 2002 & 3636 & 2237 & 3935 \\
\hline Actg1 K.O. & 2081 & 3511 & 1225 & 2652 \\
\hline Actb K.O. & 584 & 1155 & 703 & 1110 \\
\hline
\end{tabular}

C

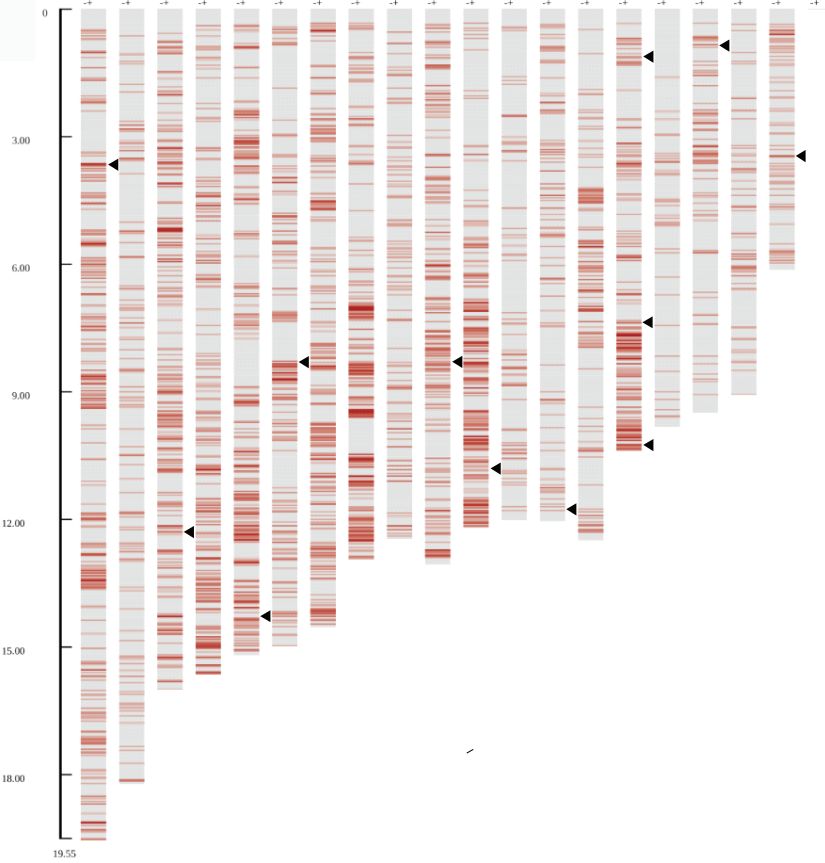

bioRxiv preprint doi: https://doi.org/10.1101/328153; this version posted May 22 2018 . The copyright holder for the preprint (which was not certified by peer review) is the author/funder, who has granted bioRxiv a license to display the preprint in perpetuity. It is made avallable under aCC-BY-NC-ND 4.0 International license. $\equiv-$ - d

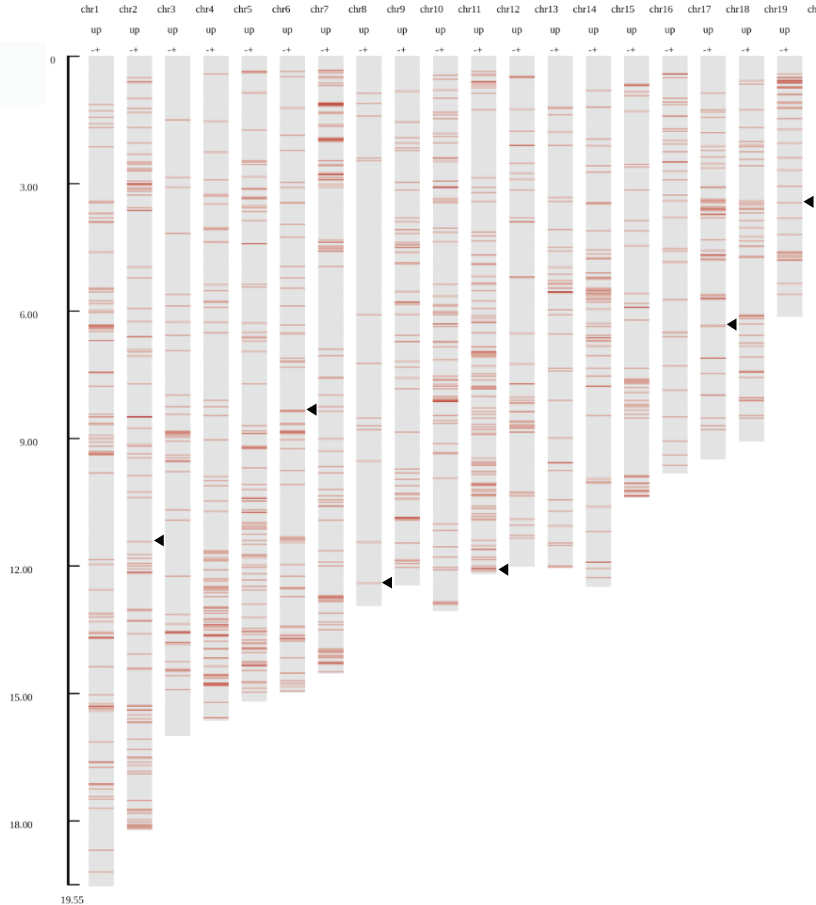

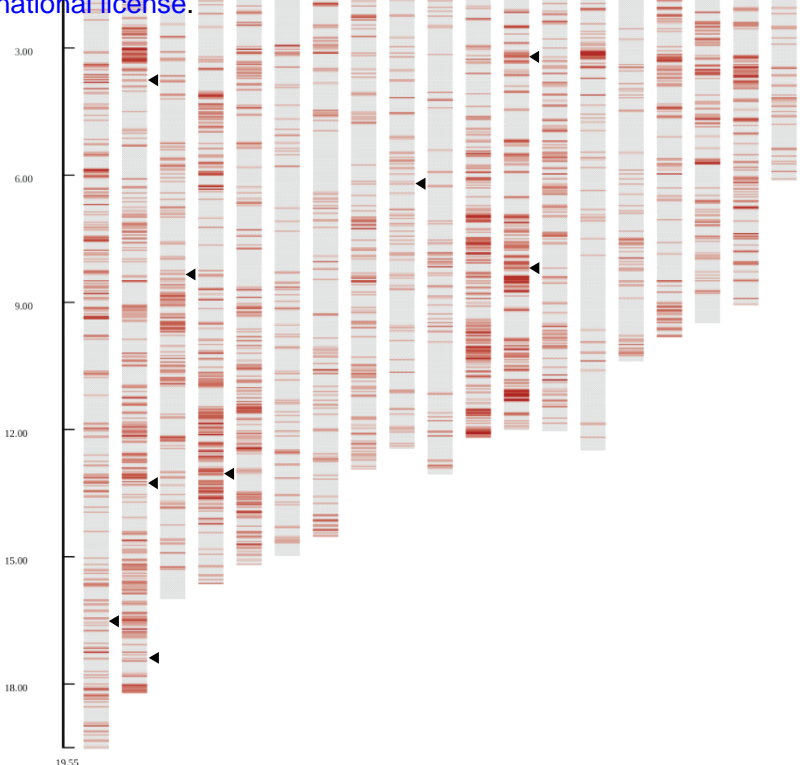

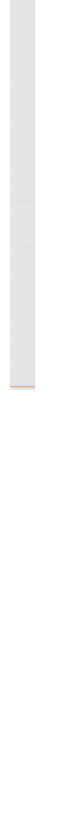


bioRxiv preprint doi: https://doi.org/10.1101/328153; this version posted May 22, 2018. The copyright holder for this preprint (which was not certified by peer review) is the author/funder, who has granted bioRxiv a license to display the preprint in perpetuity. It is made available under aCC-BY-NC-ND 4.0 International license.

\begin{tabular}{|c|c|c|c|}
\hline Gene & L2F K2 K.O./wt & Pval & Padj \\
\hline Fermt1 & 8,055307305 & $5,19 E-43$ & $1,94 \mathrm{E}-41$ \\
\hline Dchs2 & 3,501304705 & $4,92 E-11$ & 3,99E-10 \\
\hline Paqr5 & 1,679449433 & $2,46 \mathrm{E}-13$ & 2,41E-12 \\
\hline Mlxipl & 0,618877214 & 0,409259 & 0,573342 \\
\hline Pcnx & 0,502076808 & $8,12 \mathrm{E}-06$ & $3,76 \mathrm{E}-05$ \\
\hline Nkain1 & 0,39205614 & 0,043898 & 0,097439 \\
\hline Vapb & 0,386807243 & 2,47E-06 & $1,22 \mathrm{E}-05$ \\
\hline Strbp & 0,273294934 & 0,000195 & 0,000738 \\
\hline Prkar2b & 0,271409666 & 0,006358 & 0,017971 \\
\hline Pou2f1 & 0,191075348 & 0,041339 & 0,092619 \\
\hline Depdc1b & 0,097436998 & 0,581669 & 0,726092 \\
\hline Fermt3 & 0,035722034 & 0,948806 & 0,970063 \\
\hline$M f s d 11$ & $-0,085901914$ & 0,621497 & 0,757444 \\
\hline Trim24 & $-0,255516547$ & 0,00941 & 0,025447 \\
\hline Atm & $-0,516886899$ & $3,84 \mathrm{E}-13$ & $3,70 \mathrm{E}-12$ \\
\hline Slc25a13 & $-0,678800185$ & 1,40E-06 & 7,14E-06 \\
\hline Abhd18 & $-0,82015185$ & 0,024339 & 0,05872 \\
\hline Eda & $-1,503214668$ & 0,167483 & 0,294635 \\
\hline
\end{tabular}

C

\begin{tabular}{|l|r|r|r|}
\hline Gene & L2F Actb K.O./wt & Pval & \multicolumn{1}{l}{ Padj } \\
\hline Acta2 & 7,948538835 & $5,34 \mathrm{E}-151$ & $7,98 \mathrm{E}-147$ \\
\hline Actg2 & 2,961946198 & 0,020429 & 1 \\
\hline Acta1 & 2,556443324 & 0,001842 & 0,036378 \\
\hline Actc1 & 2,284580096 & 0,017007 & 1 \\
\hline Ras/2-9 & 1,353877161 & 0,350521 & 1 \\
\hline Actg1 & 0,982444337 & $3,78 \mathrm{E}-11$ & $7,63 \mathrm{E}-09$ \\
\hline Pde10a & 0,552114557 & 0,432741 & 0,833262 \\
\hline Fbxl17 & 0,524667754 & 0,032681 & 0,244749 \\
\hline Gm17087 & 0,158304112 & 0,936537 & 0,989226 \\
\hline Lrrc58 & 0,028544142 & 0,851949 & 0,974102 \\
\hline
\end{tabular}

b

\begin{tabular}{|l|rrr|}
\hline Gene & \multicolumn{1}{l}{ L2F Actg1 K.O./wt } & \multicolumn{2}{l}{ Pval } \\
\hline Actg2 & 5,86 & 0 & 0 \\
\hline Ptp4a3 & 3,91 & 0,00000246 & $1,40 \mathrm{E}-05$ \\
\hline Hcn1 & 3,47 & $1,84 \mathrm{E}-09$ & $1,45 \mathrm{E}-08$ \\
\hline Adamts12 & 2,14 & $4,91 \mathrm{E}-46$ & $2,53 \mathrm{E}-44$ \\
\hline Sec24d & 0,81 & $4,36 \mathrm{E}-20$ & $7,67 \mathrm{E}-19$ \\
\hline Acta2 & 0,76 & $6,48 \mathrm{E}-45$ & $3,22 \mathrm{E}-43$ \\
\hline Hcfc2 & 0,72 & $2,91 \mathrm{E}-08$ & $2,05 \mathrm{E}-07$ \\
\hline Ubap1l & 0,45 & 0,573535144 & 0,743877533 \\
\hline Pde10a & 0,44 & 0,000216157 & 0,000933738 \\
\hline Nol11 & 0,43 & $9,8 \mathrm{E}-11$ & $8,69 \mathrm{E}-10$ \\
\hline Actr1b & 0,29 & 0,000631774 & 0,002508725 \\
\hline Atf7 & 0,29 & 0,002212762 & 0,007853264 \\
\hline Actb & 0,19 & 0,000162494 & 0,00071632 \\
\hline Znrf2 & 0,13 & 0,270233353 & 0,458179229 \\
\hline Lrrc58 & $-0,15$ & 0,019456235 & 0,054271242 \\
\hline Fmnl2 & $-0,2$ & 0,008174843 & 0,025396546 \\
\hline Cdk12 & $-0,24$ & 0,000463124 & 0,001889135 \\
\hline Actr1a & $-0,28$ & 0,000780469 & 0,003040052 \\
\hline Fbxl17 & $-0,49$ & 0,00000017 & 0,000284708 \\
\hline Grpel2 & $-0,58$ & 0,0000601 & 0,45255246 \\
\hline Acta1 & $-1,91$ & $1,01 \mathrm{E}-25$ & $2,36 \mathrm{E}-24$ \\
\hline
\end{tabular}


bioRxiv preprint doi: https://doi.org/10.1101/328153; this version posted May 22, 2018. The copyright holder for this preprint (which was not certified by peer review) is the author/funder, who has granted bioRxiv a license to display the preprint in perpetuity. It is made available under aCC-BY-NC-ND 4.0 International license.

\section{hif1ab mRNA (ENSDART00000018500)}

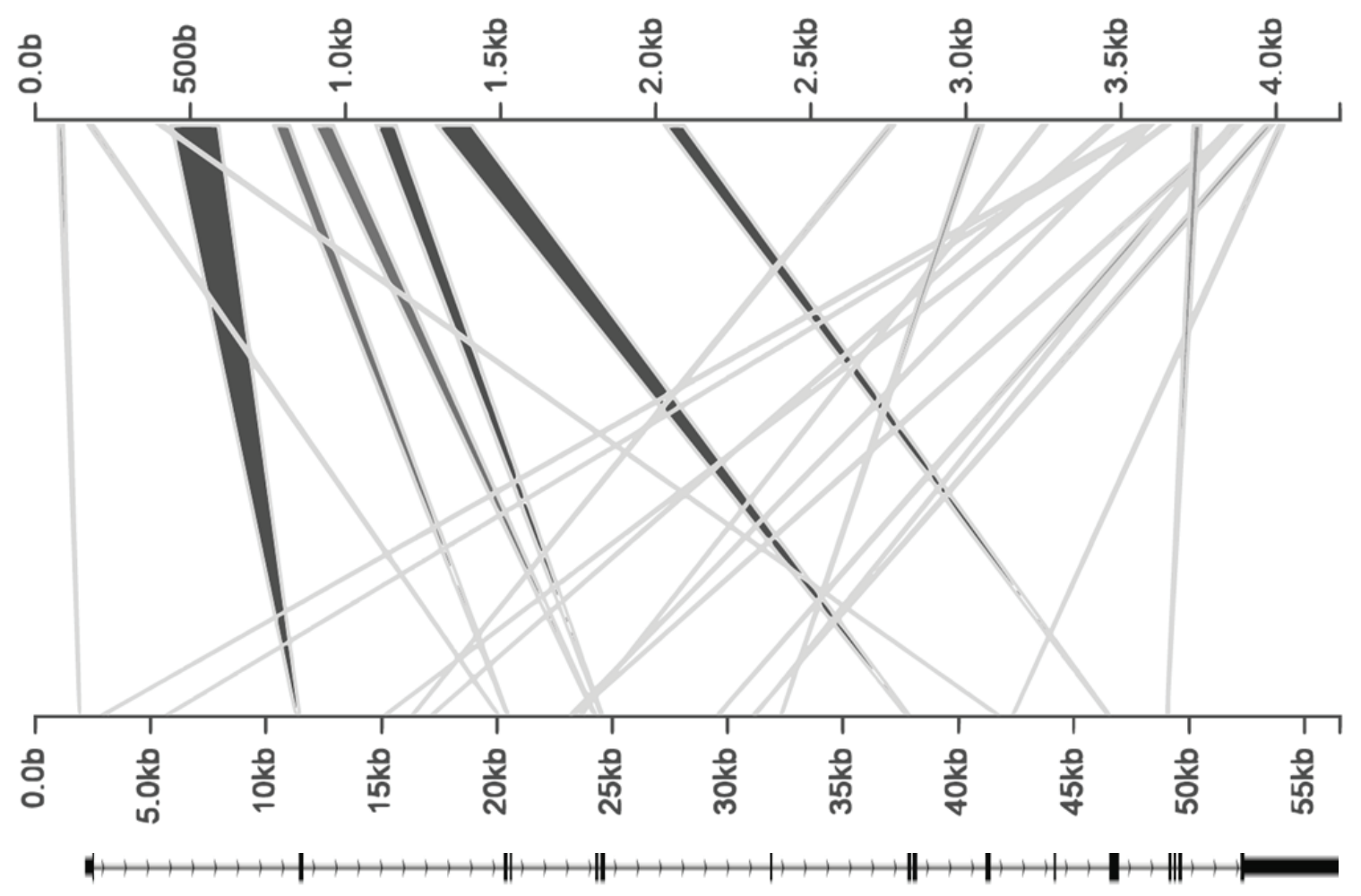

epas1a genomic locus $+2 \mathrm{~kb}$ upstream of TSS (ENSDARG00000008697) 
bioRxiv preprint doi: https://doi.org/10.1101/328153; this version posted May \$2, 2018. The copyright holder for this preprint (which was not certified by peer review) is the author/funder, who has granted bioRxiv a license to display the preprint in perpetuity. It is made available under
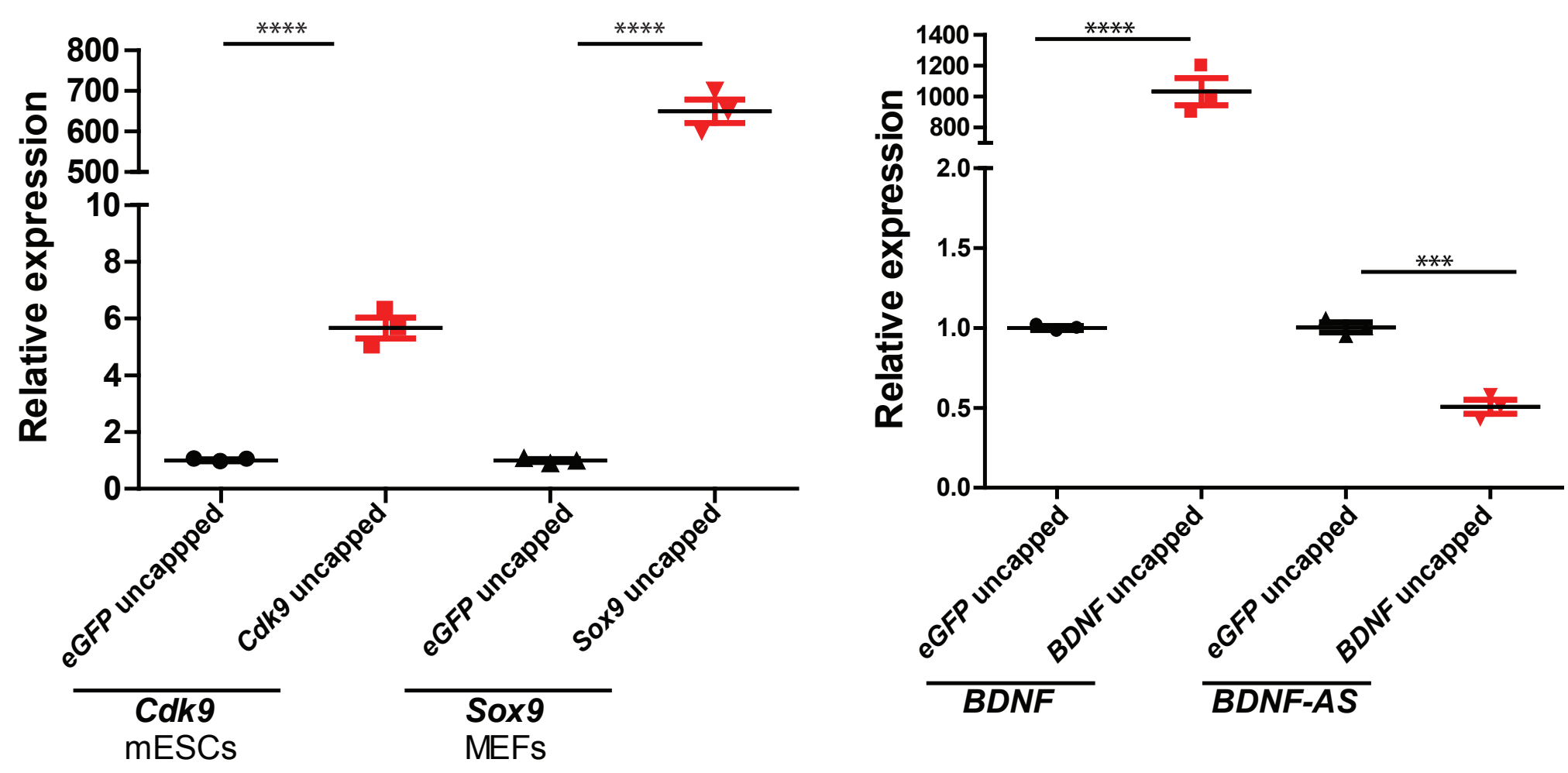